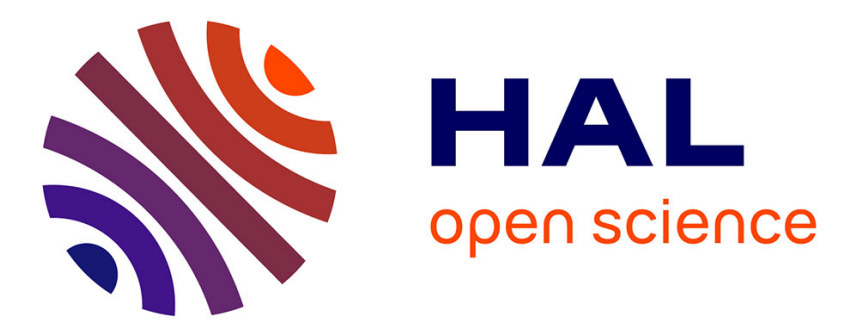

\title{
The remarkable effect of the preparation procedure on the catalytic activity of CoBEA zeolites in the Fischer-Tropsch Synthesis
}

Karolina A. Chalupka, Sandra Casale, Ewa Zurawicz, Jacek Rynkowski, Stanislaw Dzwigaj

\section{To cite this version:}

Karolina A. Chalupka, Sandra Casale, Ewa Zurawicz, Jacek Rynkowski, Stanislaw Dzwigaj. The remarkable effect of the preparation procedure on the catalytic activity of CoBEA zeolites in the Fischer-Tropsch Synthesis. Microporous and Mesoporous Materials, 2015, 211, pp.9-18. 10.1016/j.micromeso.2015.02.024 . hal-01130202

\section{HAL Id: hal-01130202 https://hal.sorbonne-universite.fr/hal-01130202}

Submitted on 11 Mar 2015

HAL is a multi-disciplinary open access archive for the deposit and dissemination of scientific research documents, whether they are published or not. The documents may come from teaching and research institutions in France or abroad, or from public or private research centers.
L'archive ouverte pluridisciplinaire HAL, est destinée au dépôt et à la diffusion de documents scientifiques de niveau recherche, publiés ou non, émanant des établissements d'enseignement et de recherche français ou étrangers, des laboratoires publics ou privés. 


\section{Graphical Abstract}

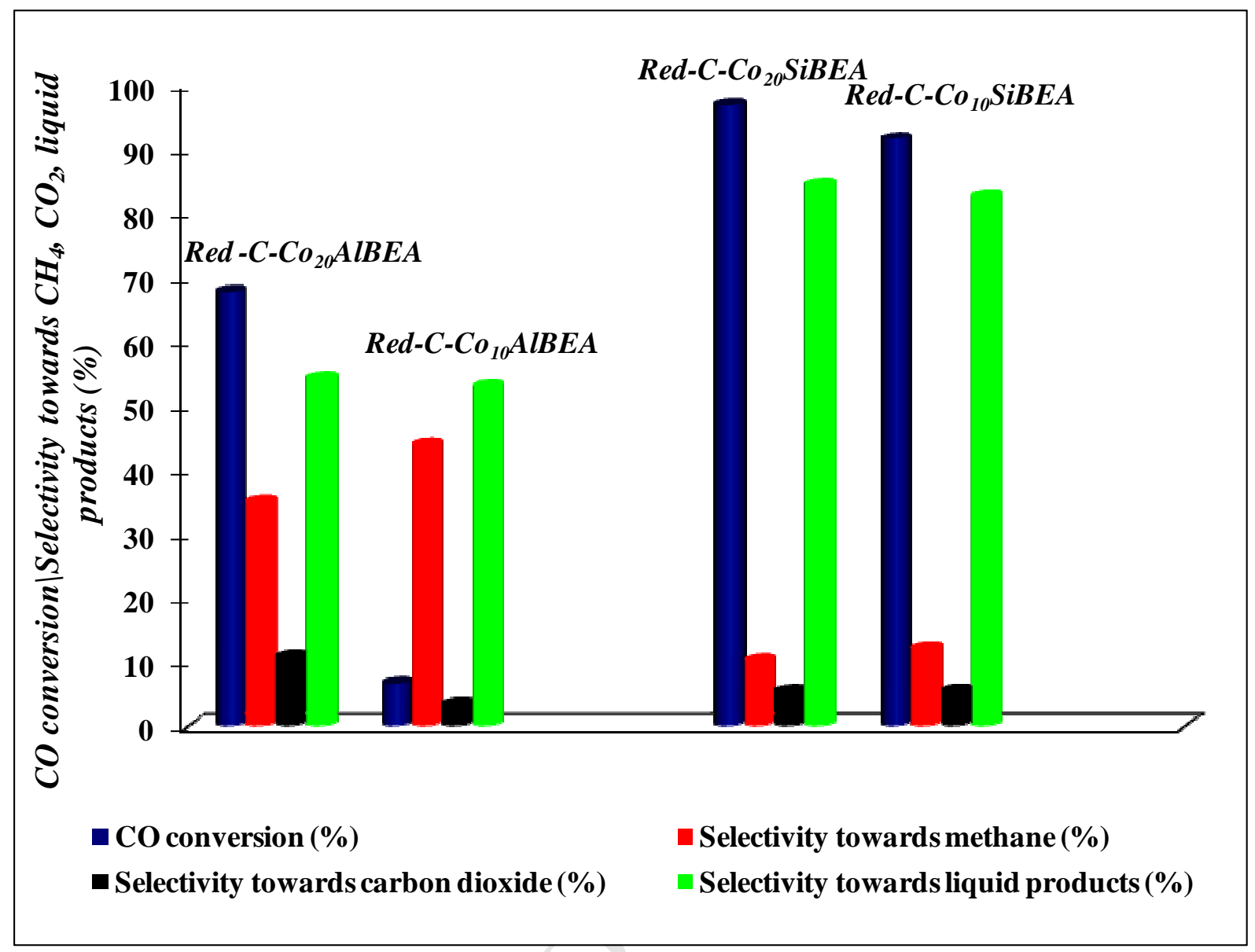


The remarkable effect of the preparation procedure on the catalytic activity of CoBEA zeolites in the Fischer-Tropsch Synthesis

\author{
Karolina A. Chalupka ${ }^{1, *}$, Sandra Casale ${ }^{2,3}$, Ewa Zurawicz ${ }^{1}$, \\ Jacek Rynkowski ${ }^{1}$, Stanislaw Dzwigaj ${ }^{2,3 *}$
}

${ }^{1}$ Lodz University of Technology, Institute of General and Ecological Chemistry, Zeromskiego 116, 90 - 924 Lodz, Poland

${ }^{2}$ Sorbonne Universités, UPMC Univ Paris 06, UMR 7197, Laboratoire de Réactivité de Surface, F-75005, Paris, France

${ }^{3}$ CNRS, UMR 7197, Laboratoire de Réactivité de Surface, F-75005, Paris, France

Figures: 14

Tables: 4

Keywords: Co, BEA, CO, $\mathrm{H}_{2}$, Fischer - Tropsch Synthesis

*Corresponding authors:

Karolina Chalupka, karolina.chalupka@p.lodz.pl, tel. + 48426313134

Stanislaw Dzwigaj, stanislaw.dzwigaj@upmc.fr, $\quad$ tel. + 33144272113 


\section{Abstract}

This work deals with the investigation of the influence of the preparation procedure and Co content on the activity of CoBEA zeolite in Fischer - Tropsch synthesis. For this purpose the Co-containing zeolites were prepared by a conventional wet impregnation $\left(\mathrm{Co}_{\mathrm{x}} \mathrm{AlBEA}\right.$ series) and a two-step postsynthesis method $\left(\mathrm{Co}_{\mathrm{x}} \mathrm{SiBEA}\right.$ series). Calcination at $500{ }^{\circ} \mathrm{C}$, for $3 \mathrm{~h}$ in air and then reduction at $500{ }^{\circ} \mathrm{C}$ in flow of $95 \% \mathrm{H}_{2}-5 \% \mathrm{Ar}$ stream of as prepared $\mathrm{Co}_{\mathrm{x}} \mathrm{AlBEA}$ and $\mathrm{Co}_{\mathrm{x}} \mathrm{SiBEA}$ zeolites led to obtain Red-C-Co $\mathrm{ClBEA}$ and Red-C-Co $\mathrm{SiBEA}$ catalysts with different properties in Fischer - Tropsch reaction. The most active catalysts were Red-C-Co ${ }_{10} \mathrm{SiBEA}$ and Red-C-Co ${ }_{20} \mathrm{SiBEA}$ with high CO conversion of $90-95 \%$ and selectivity towards liquid products of $85 \%$ containing $\mathrm{C}_{7}-\mathrm{C}_{18} \mathrm{n}$-alkanes, isoalkanes and small amount of olefins. In the case of Red-C-Co ${ }_{x}$ AlBEA catalysts the CO conversion was of $68 \%$ and selectivity towards liquid products of $57 \%$. The identified liquid products were mainly $\mathrm{C}_{7}-\mathrm{C}_{16}$ n-alkanes. Moreover, Red-C-Co $\mathrm{S}$ SiBEA catalysts demonstrated better stability and resistance to coke formation than Red-C-Co $\mathrm{AlBEA}$ ones. It is probably related to higher dispersion of cobalt nanoparticles in Red-C-Co $\mathrm{CiBEA}_{\mathrm{x}}$ than in Red-C-Co $\mathrm{AlBEA}$ catalysts and absence of strong Brønsted acidic sites in the former after removal of aluminium in the first step of two-step postsynthesis preparation procedure. 


\section{Introduction}

The Fischer - Tropsch synthesis (FTS) is a process, in which saturated and unsaturated liquid hydrocarbons are produced from synthesis gas [1-3]. It is the process of great importance due to the possibility of alternative fuels production.

Cobalt and iron supported on $\mathrm{SiO}_{2}, \mathrm{Al}_{2} \mathrm{O}_{3}$ or $\mathrm{TiO}_{2}$ are widely used as catalysts of Fischer - Tropsch synthesis [2, 4]. In the last time the zeolites are also used as the catalyst supports in FTS [4]. It was shown [2, 4] that high activity and selectivity of supported cobalt catalysts in FT reaction depend on amount of active centers present on catalysts surface as metallic cobalt nanoparticles. Very often the activity of supported cobalt catalysts depends on the metal dispersion and reduction state of $\mathrm{Co}_{3} \mathrm{O}_{4}$ phase $[2,4]$.

Usually, the application of supported cobalt and iron catalysts in FT synthesis leads to the formation of linear hydrocarbons and waxes. Such liquid products have high cetane number but very low octane number. To obtain hydrocarbons with higher octane number zeolites modified by cobalt was applied as potential FTS catalysts. These zeolites materials have several advantages, such as high surface area, micro - and mesoporous structure, which can improve metal dispersion and thus lead to obtain smaller size of metal nanoparticles. Additionally, their well known catalytic properties in cracking can cause a decrease of selectivity toward long-chain paraffins and an increase of selectivity towards shorter-chain of saturated and unsaturated hydrocarbons. In consequence, one can expect an increase in the octane number of liquid products of FT synthesis [2, 4-7].

As it was recently shown [8,9], the physicochemical properties of catalyst, such as, reducibility of supported cobalt species, a presence of mononuclear Co species and cobalt dispersion have strong impact on catalysts activity in FT synthesis. This knowledge makes easier the optimalization and design of new industrial catalysts. 
Supported metal/BEA zeolite catalysts were investigated in FT reaction due to the presence of acidic sites, which can increase the activity and selectivity of catalysts in $\mathrm{CO}$ hydrogenation $[10,11]$. The modification of BEA zeolite by dealumination followed by the introduction of transition metals can improve the activity of cobalt zeolite catalysts in Fischer-Tropsch synthesis and enable the selective production of liquid hydrocarbons.

This work is focused on the determination of physicochemical properties and catalytic performance in FT reaction of CoBEA zeolite materials prepared by conventional wet impregnation and two-step postsynthesis procedures. The activity of Red-C-Co $\mathrm{AlBEA}$ zeolite catalysts prepared from HAlBEA zeolite containing Brønsted acidic sites is compared with that of Red-C-Co $\mathrm{SiBEA}$ zeolite catalysts prepared from SiBEA zeolite that do not contain this type of acidic sites. The remarkable effect of the two-step postsynthesis procedure on the catalytic activity of CoSiBEA zeolites in the Fischer-Tropsch Synthesis has been demonstrated in this work.

\section{Experimental part}

\subsection{Samples preparation}

The series of $\mathrm{Co}_{\mathrm{x}} \mathrm{AlBEA}$ and $\mathrm{Co}_{\mathrm{x}} \mathrm{SiBEA}$ zeolites (where $\mathrm{x}=10$ and $20 \mathrm{Co}$ wt $\%$ ) were prepared by conventional wet impregnation and two-step postsynthesis procedure, respectively [12-14].

Tetraethylammonium BEA (TEABEA) zeolite provided by RIPP (China) was divided into two fractions. The first one was calcined (air, $15 \mathrm{~h}, 550{ }^{\circ} \mathrm{C}$ ) in order to obtain an organic free AlBEA zeolite $(\mathrm{Si} / \mathrm{Al}=12.5)$. The $\mathrm{Co}_{\mathrm{x}} \mathrm{AlBEA}$ zeolites were prepared by impregnation of AlBEA with an aqueous solution of $\mathrm{Co}\left(\mathrm{NO}_{3}\right)_{2} \cdot 6 \mathrm{H}_{2} \mathrm{O}(\mathrm{pH}=2.6)$ under aerobic conditions [12-14]. Then the suspensions were stirred at $80{ }^{\circ} \mathrm{C}$ for $2 \mathrm{~h}$ until water was evaporated and 
the resulting solids were dried in air at $80{ }^{\circ} \mathrm{C}$ for $24 \mathrm{~h}$, calcined in air at $500{ }^{\circ} \mathrm{C}$ for $3 \mathrm{~h}$ and labelled C-Co ${ }_{x}$ AlBEA.

The second fraction of TEABEA was treated in a $13 \mathrm{~mol}{ }^{-1} \mathrm{~L}^{-1} \mathrm{HNO}_{3}$ aqueous solution (4 $\left.\mathrm{h}, 80{ }^{\circ} \mathrm{C}\right)$ to obtain a dealuminated and organic - free SiBEA support $(\mathrm{Si} / \mathrm{Al}=1300)$ with vacant $\mathrm{T}$-atom sites (where $\mathrm{T}=\mathrm{Al}$ ). SiBEA was then separated by centrifugation, washed with distilled water and dried overnight at $80{ }^{\circ} \mathrm{C}$. To incorporate $\mathrm{Co}^{2+}$ ions in vacant $\mathrm{T}$-atom sites, $2 \mathrm{~g}$ of SiBEA was stirred under aerobic conditions for $24 \mathrm{~h}$ at $25{ }^{\circ} \mathrm{C}$ in $200 \mathrm{~mL}$ of $\mathrm{Co}\left(\mathrm{NO}_{3}\right)_{2} \cdot 6 \mathrm{H}_{2} \mathrm{O}$ aqueous solution $(\mathrm{pH}=2.4-2.6)$ with different concentrations to obtain the solids with various Co content [12-14]. Then, the suspensions were stirred for $2 \mathrm{~h}$ at $80{ }^{\circ} \mathrm{C}$ until water was evaporated and the resulting solids were dried in air at $80{ }^{\circ} \mathrm{C}$ for $24 \mathrm{~h}$ and labelled as $\mathrm{Co}_{\mathrm{x}} \mathrm{SiBEA}$. Then, the solids were calcined in air at $500{ }^{\circ} \mathrm{C}$ for $3 \mathrm{~h}$ and labelled $\mathrm{C}-\mathrm{Co}_{\mathrm{x}} \mathrm{SiBEA}$.

Before FT reaction tests, C-Co $\mathrm{AlBEA}$ and $\mathrm{C}-\mathrm{Co}_{\mathrm{x}} \mathrm{SiBEA}$ were treated in situ under atmospheric pressure in flow of $95 \% \mathrm{H}_{2}-5 \%$ Ar stream at $500{ }^{\circ} \mathrm{C}$ for $1 \mathrm{~h}$ and such obtained catalysts were labelled as Red-C-Co $\mathrm{C}_{\mathrm{x}} \mathrm{AlBEA}$ and Red-C-Co $\mathrm{O}_{\mathrm{x}} \mathrm{SiBEA}$, respectively.

\subsection{Methods of samples characterization}

DR UV-Vis spectra were recorded under ambient atmosphere on a Cary 5000 Varian spectrometer equipped with a double integrator with polytetrafluoroethylene as reference.

Powder $\mathrm{X}$ - ray diffractograms were recorded on a Bruker D8 ADVANCE using $\mathrm{Cu} \mathrm{K}_{\alpha}$ radiation $(\lambda=154,05 \mathrm{pm})$ in $2 \theta$ range of $5-90^{\circ}$.

The TPR $-\mathrm{H}_{2}$ measurements were carried out in an automatic TPR system (AMI-1) in the temperature range of $25-900{ }^{\circ} \mathrm{C}$, using $\mathrm{H}_{2}$ stream $\left(5 \% \mathrm{H}_{2}-95 \% \mathrm{Ar}\right.$, flow $\left.40 \mathrm{~mL} \cdot \mathrm{min}^{-1}\right)$. $\mathrm{H}_{2}$ consumption was monitored by a thermal conductivity detector (TCD). 
The TPD $-\mathrm{NH}_{3}$ measurements were carried out in a quartz reactor using gaseous ammonium. $\mathrm{NH}_{3}$ was adsorbed on zeolite catalysts at $100{ }^{\circ} \mathrm{C}$ for 10 minutes in flowing $\mathrm{He}$. Before $\mathrm{NH}_{3}$ adsorption catalysts were dried at $500{ }^{\circ} \mathrm{C}$ in $\mathrm{He}$ flow for 30 minutes. The temperature programmed desorption of $\mathrm{NH}_{3}$ was carried out in the temperature range 25 $-500{ }^{\circ} \mathrm{C}$, after removing physisorbed ammonium from the catalyst.

Before FTIR Py adsorption/desorption experiments, the self-supported wafers were activated by calcination in static conditions at $723 \mathrm{~K}$ for $3 \mathrm{~h}$ in $\mathrm{O}_{2}\left(\sim 3.010^{4} \mathrm{~Pa}\right)$ and then outgassed under secondary vacuum at $573 \mathrm{~K}\left(10^{-3} \mathrm{~Pa}\right)$ for $1 \mathrm{~h}$. These wafers were contacted at room temperature with gaseous $\mathrm{Py}(133 \mathrm{~Pa})$ via a separate cell containing liquid Py. The spectra were then recorded following desorption from 423 and $573 \mathrm{~K}$ with a Bruker Vector 22 spectrometer (resolution $2 \mathrm{~cm}^{-1}, 128$ scans). The reported spectra were obtained after subtraction of the spectrum recorded before Py adsorption.

The crystal morphology and the size of nanoparticles of $\mathrm{Co}(0)$ formed in $\mathrm{C}-\mathrm{Co}_{\mathrm{x}} \mathrm{AlBEA}$ and $\mathrm{C}-\mathrm{Co}_{\mathrm{x}} \mathrm{SiBEA}$ upon TPR $-\mathrm{H}_{2}$ experiment were identified by TEM (JEM-100 CX II ELECTRON MICROSCOPE, JEOL).

Thermal analysis data (SETSYS 16/18, Setaram (France) and mass spectrometer ThermoStar, Balzers (Germany)) were used to define the formation of carbon deposit. The measurements were made in the range of $25-1000{ }^{\circ} \mathrm{C}$ in flowing air.

\subsection{Catalytic tests}

The FT catalytic tests were carried out in a fixed bed reactor using a gas mixture of $\mathrm{H}_{2}$ and $\mathrm{CO}$ with molar ratio $2 / 1$ and total flow of reagents $60 \mathrm{~mL} \cdot \mathrm{min}^{-1}$. Reaction was carried out under $30 \mathrm{~atm}$ at $260{ }^{\circ} \mathrm{C}$ and gaseous reagents were analyzed by GC gas chromatograph (Shimadzu GC - 14) equipped with TCD detector and two columns: measuring - Carbosphere 7A and comparative - molecular sieves 7B. Parameters of GC 


\section{ACCEPTED MANUSCRIPT}

measurements: column's temperature $-45^{\circ} \mathrm{C}$, detector's temperature $-120{ }^{\circ} \mathrm{C}$, detector's current - $100 \mathrm{~mA}$; carried gas - He. Before FT reaction, catalysts were reduced in situ under atmospheric pressure in a flow of $95 \% \mathrm{H}_{2}-5 \%$ Ar gas mixture at $500{ }^{\circ} \mathrm{C}$ for $1 \mathrm{~h}$. The liquid products were analyzed by GC - MS coupled technique. Gas chromatograph (6890N Network GC) was equipped with capillary column HP - 5MS (Agilent Technology) and coupled with quadrupole mass spectrometer (5973 Network Mass Selective Detector). The liquid products in the aim of water removal, which could formed during reaction, were concentrated by SPE method on octadecyl columns C18. Before extraction each of column was preconditioned with $2 \mathrm{~mL}$ of $\mathrm{n}$ - hexane. After this process $1 \mathrm{~mL}$ of liquid products sample were injected on column and then it was washed with $2 \mathrm{~mL}$ of $\mathrm{n}-$ hexane. GC - MS analysis were carried out in helium flow $\left(0.7 \mathrm{~mL} \cdot \mathrm{min}^{-1}\right)$ in temperature range $60-280{ }^{\circ} \mathrm{C}$ with linear temperature increase of $10^{\circ} \mathrm{C} \min ^{-1}$. The volume of analyzed sample was $1 \mathrm{~mm}^{3}$.

The quantitative analysis of $\mathrm{CO}$ conversion $\left(\mathrm{K}_{\mathrm{CO}}\right)$ and selectivity towards $\mathrm{CO}_{2}\left(\mathrm{~S}_{\mathrm{CO} 2}\right)$, $\mathrm{CH}_{4}\left(\mathrm{~S}_{\mathrm{CH} 4}\right)$ and liquid products $\left(\mathrm{S}_{\mathrm{LP}}\right)$ were calculated in the following way:

$$
\begin{aligned}
& \mathbf{K}_{\mathrm{CO}}=\frac{\mathbf{s}_{\mathrm{COin}}-\mathbf{s}_{\mathrm{COari}}}{\mathbf{s}_{\mathrm{COin}}} * 100 \% \\
& \mathbf{s}_{\mathrm{CH}_{4}}=\frac{\mathbf{x}_{\mathrm{CH}_{4} \mathrm{i}} * 100 \%}{\mathbf{x}_{\mathrm{CH}_{4} \text { out }}} / \mathbf{F} \\
& \mathbf{x}_{\mathrm{CH}_{4} \text { out }}=\frac{\mathbf{X}_{\mathrm{CH}_{4} \xi^{3}}+\mathbf{K}_{\mathrm{CO}}}{100 \%} \\
& \mathbf{s}_{\mathrm{CO}_{2}}=\frac{\mathbf{X}_{\mathrm{CO}_{\mathrm{z}^{\mathrm{i}}}} * \mathbf{1 0 0} \%}{\mathbf{X}_{\mathrm{CO}_{2} \text { out }}} / \mathbf{F} \\
& \mathbf{x}_{\mathrm{CO}_{2} \text { out }}=\frac{\mathbf{x}_{\mathrm{CO}_{2 s}} * \mathbf{K}_{\mathrm{Co}}}{100 \%}
\end{aligned}
$$

where: $\mathrm{K}_{\mathrm{CO}}-\mathrm{CO}$ conversion

$\mathrm{S}_{\mathrm{COin}}-$ the peak's surface of $\mathrm{CO}$ on inlet before reaction (standard) 
$\mathrm{S}_{\mathrm{COari}}$ - the peak's surface of $\mathrm{CO}$ after reaction

$\mathrm{S}_{\mathrm{CH} 4}-$ selectivity towards $\mathrm{CH}_{4}$

$\mathrm{S}_{\mathrm{CO} 2}-$ selectivity towards $\mathrm{CO}_{2}$

$\mathrm{X}_{\mathrm{CH} 4 \mathrm{i}}$ - the peak's surface of $\mathrm{CH}_{4}$ formed during reaction

$\mathrm{X}_{\mathrm{CO} 2 \mathrm{i}}$ - the peak's surface of $\mathrm{CO}_{2}$ formed during reaction

$\mathrm{X}_{\mathrm{CH} 4 \text { out }}$ - the teorethical peak's surface of $\mathrm{CH}_{4}$ which could be formed during reaction in the case when all $\mathrm{CO}$ is converted to $\mathrm{CH}_{4}$

$\mathrm{X}_{\mathrm{CO} \text { out }}$ - the teorethical peak's surface of $\mathrm{CO}_{2}$ which could be formed during reaction in the case when all $\mathrm{CO}$ is converted to $\mathrm{CO}_{2}$

$\mathrm{X}_{\mathrm{CH} 4 \mathrm{~s}}$ - the peak's surface of $\mathrm{CH}_{4}$ standard when only methane is analyzed

$\mathrm{X}_{\mathrm{CO} 2 \mathrm{~s}}$ - the peak's surface of $\mathrm{CO}_{2}$ standard when only carbon dioxide is analyzed

F - contraction coefficient taken into account the changes of flow and

differences between gaseous substrates and liquid products:

$$
\mathbf{F}=\frac{\mathbf{S}_{\mathrm{Ar} \mathbf{i}}}{\mathbf{S}_{\mathrm{Ar} \mathbf{s}}}
$$

$\mathrm{S}_{\mathrm{Ar} \text { i }}$ - peak's surface of Ar (inert gas) during reaction

$\mathrm{S}_{\mathrm{Ars}}$ - peak's surface of Ar on inlet before reaction (standard)

The $\mathrm{C}_{2}-\mathrm{C}_{6}$ hydrocarbons were not identified during $\mathrm{GC}$ analysis. The selectivity towards liquid products (all formed liquid products) was calculated from following equation:

$$
\mathrm{S}_{\mathrm{LP}}=100-\left(\mathrm{S}_{\mathrm{CH} 4}+\mathrm{S}_{\mathrm{CO} 2}\right)
$$

\section{Results and discussion}

3.1. The state and nature of cobalt in Co $\mathrm{o}_{\mathrm{x}} \mathrm{SiBEA}$ and $\mathrm{Co}_{\mathrm{x}} \mathrm{AIBEA}$ as determined by DR UV-vis and XRD studies 
In Figure 1 the DR UV - vis spectra of as prepared $\mathrm{Co}_{20} \mathrm{AlBEA}, \mathrm{Co}_{10} \mathrm{SiBEA}$ and CoSiBEA are presented. For both series, the bands between 515 and $455 \mathrm{~nm}$ are observed, which can be assigned to octahedral Co(II) species ( $3 \mathrm{~d}^{7}$ configuration) and/or cobalt oxides, in line with earlier reports on Co-containing zeolites [12 - 16].

- Figure 1 -

Similar bands were observed for Co-MFI and Co-APO-5 zeolites $[12-14,17-20]$. For all studied zeolites, the band at $300 \mathrm{~nm}$ appears, which is related to charge transfer (CT) transition between oxygen and cobalt in pseudo-tetrahedral and/or octahedral Co(II), in line with earlier reports [12-14, 21, 22].

For C-Co ${ }_{10} \mathrm{AlBEA}, \mathrm{C}-\mathrm{Co}_{20} \mathrm{AlBEA}$ and $\mathrm{Co}_{10} \mathrm{SiBEA}$ and $\mathrm{Co}_{20} \mathrm{SiBEA}$ a significant difference in the DR UV-vis spectra are observed that can be related to the methods of their preparation. As shown in Fig. 2, $\mathrm{Co}_{20} \mathrm{SiBEA}$ prepared by two-step postsynthesis procedure exhibits three kinds of cobalt species, the isolated pseudo-tetrahedral Co (II) (band at 640 $\mathrm{nm}$ ), octahedral Co (II) (band at $511 \mathrm{~nm}$ ) and cobalt oxides (band at $464 \mathrm{~nm}$ ). For $\mathrm{Co}_{20} \mathrm{AlBEA}$ only broad band of octahedral Co (II) and/or cobalt oxides at $460 \mathrm{~nm}$ are observed.

- Figure 2 -

The DR UV - vis results show that dealumination of BEA zeolite leads to better dispersion of cobalt species in $\mathrm{Co}_{20} \mathrm{SiBEA}$ containing different cobalt species: isolated pseudo-tetrahedral Co (II), octahedral Co (II) and cobalt oxides. In contrast, the introduction of high amounts of cobalt into AlBEA leads to obtain $\mathrm{Co}_{\mathrm{x}} \mathrm{AlBEA}$ with octahedral $\mathrm{Co}(\mathrm{II})$ and cobalt oxides as shown, for example for $\mathrm{Co}_{10} \mathrm{AlBEA}$ in Fig. 2.

Figures 3 and 4 present XRD diffractograms of $\mathrm{C}-\mathrm{Co}_{10} \mathrm{AlBEA}$ and $\mathrm{C}-\mathrm{Co}_{20} \mathrm{AlBEA}$ (Fig. 3) and $\mathrm{C}-\mathrm{Co}_{10} \mathrm{SiBEA}$ and $\mathrm{C}-\mathrm{Co}_{20} \mathrm{SiBEA}$ (Fig. 4). For these samples the lines characteristic for BEA zeolite $\left(2 \theta=22.4^{\circ}\right)$ and $\mathrm{Co}_{3} \mathrm{O}_{4}\left(2 \theta=36.7 ; 58.6 ; 64.6^{\circ}\right)$ are observed. The similar lines 
related to the presence of $\mathrm{Co}_{3} \mathrm{O}_{4}$ were obtained by A. Martinez and G. Prieto for ITQ - 2 zeolite containig $10 \mathrm{Co}$ wt $\%$ (with highest intensity for $2 \theta=36.7^{\circ}$ ) [28].

-Figure 3 -

-Figure 4 -

\subsection{Nature and strength of acidic centers as determined by FTIR}

To determine the nature and strength of acidic centers in both SiBEA and HAlBEA supports and, as-example, in $\mathrm{Co}_{5.0} \mathrm{SiBEA}$ and $\mathrm{Co}_{5.0} \mathrm{AlBEA}$, the FTIR spectra of adsorbed pyridine taken as probe molecules have been recorded.

The IR bands typical of pyridinium cation are observed at 1546 and $1637 \mathrm{~cm}^{-1}$ for HAlBEA (results not shown), indicating presence of Brønsted acidic sites. The other bands at about 1622, 1610, 1491 and $1455 \mathrm{~cm}^{-1}$ observed for HAlBEA correspond to pyridine interacting with Lewis acidic sites, in line with earlier data. Pyridinium cation (bands at 1546 and $1637 \mathrm{~cm}^{-1}$ ) and pyridine bonded to Lewis acidic sites (bands at 1622, 1491 and $1455 \mathrm{~cm}^{-}$ ${ }^{1}$ ) are present in the IR spectra even after outgassing of HAlBEA at $573 \mathrm{~K}$, suggesting the presence of strong Brønsted and Lewis acidic sites in this zeolite. The incorporation of Co in the HAlBEA leads to decrease the amount of Brønsted acidic sites and to increase the amount of Lewis acidic sites. Moreover, the shift of the band from 1455 (for HAlBEA) to $1450 \mathrm{~cm}^{-1}$ (for $\mathrm{Co}_{5.0} \mathrm{AlBEA}$ ) indicates a decrease of the strength of the Lewis acidic sites in zeolite when Co is incorporated in the HAlBEA.

For SiBEA, the bands characteristic of pyridinium cation and coordinatively bonded pyridine are absent in FTIR spectrum indicating the absence of Brønsted and Lewis acidic sites. By contrast, the incorporation of cobalt in SiBEA leads to appearance of the bands at 1610, 1491 and $1450 \mathrm{~cm}^{-1}$ (results not shown) suggesting the formation of new Lewis acidic sites related to the presence in this zeolite of isolated pseudo-tetrahedral $\mathrm{Co}$ (II) species. 


\subsection{The acidity of C-Co $\mathrm{Co}_{\mathrm{x}} \mathrm{SiBEA}$ and $\mathrm{C}-\mathrm{Co} \mathrm{o}_{\mathrm{x}} \mathrm{AlBEA}$ as determined by TPD - $\mathrm{NH}_{3}$ studies}

The acidity of $\mathrm{C}-\mathrm{Co}_{\mathrm{x}} \mathrm{AlBEA}$ and $\mathrm{C}-\mathrm{Co}_{\mathrm{x}} \mathrm{SiBEA}$ was investigated by TPD of $\mathrm{NH}_{3}$. The results of TPD $-\mathrm{NH}_{3}$ studies are showed in the Figures 5 and 6 and Table 2.

For C-Co ${ }_{10} \mathrm{AlBEA}$ and C-Co ${ }_{20} \mathrm{AlBEA}$ (Fig. 5), two peaks with maximum at $220{ }^{\circ} \mathrm{C}$ and $470-480{ }^{\circ} \mathrm{C}$ are seen related to the presence of weak and strong acidic sites, respectively.

- Figure 5 -

For $\mathrm{C}-\mathrm{Co}_{10} \mathrm{SiBEA}$ and $\mathrm{C}-\mathrm{Co}_{20} \mathrm{SiBEA}$ (Fig.6), the desorption peaks with the maximum at 190 and $410-430{ }^{\circ} \mathrm{C}$ are seen which can be assigned to weak and strong acidic sites, respectively. The lower temperature of high temperature desorption peaks for $\mathrm{C}-\mathrm{Co}_{10} \mathrm{SiBEA}$ and $\mathrm{C}-\mathrm{Co}_{20} \mathrm{SiBEA}$ than for $\mathrm{C}-\mathrm{Co}_{10} \mathrm{AlBEA}$ and $\mathrm{C}-\mathrm{Co}_{20} \mathrm{AlBEA}$ is related to removal of strong acidic sites upon dealumination process in the first step of two-step postsynthesis procedure.

-Figure 6 -

The quantitative TPD $-\mathrm{NH}_{3}$ results presented in Table 2 confirm that dealumination process leads to decrease acidity of BEA zeolite, in line with our ealier works [13, 14]. The amount of adsorbed $\mathrm{NH}_{3}$ is more than 2 times lower for $\mathrm{C}_{-} \mathrm{Co}_{\mathrm{x}} \mathrm{SiBEA}\left(1390 \mu \mathrm{molg}^{-1}\right.$ for C-Co ${ }_{10} \mathrm{SiBEA}$ and $1010 \mu \mathrm{molg}^{-1}$ for C-Co $\left.{ }_{20} \mathrm{SiBEA}\right)$ than for C-Co $\mathrm{X}$ AlBEA $\left(2760 \mu \mathrm{molg}^{-1}\right.$ for C-Co ${ }_{10} \mathrm{AlBEA}$ and $2440 \mu \mathrm{molg}^{-1}$ for $\left.\mathrm{C}-\mathrm{Co}_{20} \mathrm{AlBEA}\right)$. The smaller amount of adsorbed $\mathrm{NH}_{3}$ for $\mathrm{C}-\mathrm{Co}_{20} \mathrm{AlBEA}$ than for $\mathrm{C}-\mathrm{Co}_{10} \mathrm{AlBEA}$ is probably related to much stronger pore blocking by cobalt oxides in the former than in the latter.

-Table 2 -

\subsection{The reducibility of cobalt in $\mathrm{C}-\mathrm{Co}_{\mathrm{x}} \mathrm{SiBEA}$ and $\mathrm{C}-\mathrm{Co}_{\mathrm{x}} \mathrm{AIBEA}$ as determined by TPR - $\mathbf{H}_{2}$}


The TPR $-\mathrm{H}_{2}$ of C-Co ${ }_{10} \mathrm{AlBEA}$ and $\mathrm{C}-\mathrm{Co}_{20} \mathrm{AlBEA}$ (Fig. 7) and $\mathrm{C}-\mathrm{Co}_{10} \mathrm{SiBEA}$ and $\mathrm{C}-$ $\mathrm{Co}_{20} \mathrm{SiBEA}$ (Fig. 8) show that for both series the reduction process is multistage.

For $\mathrm{C}-\mathrm{Co}_{10} \mathrm{AlBEA}$ and $\mathrm{C}-\mathrm{Co}_{20} \mathrm{AlBEA}$ reduction peaks are observed at the range of 130 $600{ }^{\circ} \mathrm{C}$ with maximum at $130-160,245-290$ and $320{ }^{\circ} \mathrm{C}$ related to reduction of cobalt oxides. The peaks at $590{ }^{\circ} \mathrm{C}$ could be assigned to reduction of octahedral $\mathrm{Co}$ (II) species well dispersed in BEA structure.

- Figure 7 -

For C-Co $\mathrm{C}_{\mathrm{x}} \mathrm{SiBEA}$ two peaks observed at about $230-300{ }^{\circ} \mathrm{C}$ and $410-415{ }^{\circ} \mathrm{C}$ (Fig. 8) could be related to reduction of $\mathrm{Co}_{3} \mathrm{O}_{4}$ to metallic cobalt $\mathrm{Co}(0)$. Third reduction peak with maximum at $580{ }^{\circ} \mathrm{C}$ for $\mathrm{C}-\mathrm{Co}_{10} \mathrm{SiBEA}$ and at $630{ }^{\circ} \mathrm{C}$ for $\mathrm{C}-\mathrm{Co}_{20} \mathrm{SiBEA}$ can be assigned to reduction of octahedral $\mathrm{Co}$ (II) species. The reduction peaks at the highest temperature, at 810 ${ }^{\circ} \mathrm{C}$ for $\mathrm{C}-\mathrm{Co}_{10} \mathrm{SiBEA}$ and $760{ }^{\circ} \mathrm{C}$ for $\mathrm{C}-\mathrm{Co}_{20} \mathrm{SiBEA}$ are probably related to reduction of isolated pseudo-tetrahedral Co(II) present in framework of BEA zeolite.

-Figure 8 -

It seems that the easier reduction of cobalt in $\mathrm{C}-\mathrm{Co}_{\mathrm{x}} \mathrm{AlBEA}$ than in $\mathrm{C}-\mathrm{Co}_{\mathrm{x}} \mathrm{SiBEA}$ is related to the presence in the former of cobalt mainly in extra-framework position as cobalt oxides and in the latter of pseudo-tetrahedral Co(II) strongly bonded to zeolite structure.

\subsection{The morphology of cobalt nanoparticles as determined by TEM analysis}

In the Figure 9 the TEM images of C-Co ${ }_{20} \mathrm{AlBEA}$ (Fig. 9a) and C-Co ${ }_{20} \mathrm{SiBEA}$ (Fig. 9b) after reduction in hydrogen flow at $900{ }^{\circ} \mathrm{C}$ are presented. They show the typical shape of BEA zeolite and small $\mathrm{Co}(0)$ nanoparticles.

- Figure 9 - 
As it is shown in Table 1 , the average nanoparticles size of $\operatorname{Co}(0)$ in reduced $\mathrm{C}-\mathrm{Co}_{20} \mathrm{SiBEA}$ is $14 \mathrm{~nm}$ and is much lower than those formed in reduced $\mathrm{C}-\mathrm{Co}_{20} \mathrm{AlBEA}$ (31 $\mathrm{nm})$.

- Table 1 -

The TEM EDS analysis suggests that BEA zeolite dealumination and incorporation of Co into zeolite structure ensure very good dispersion of metal and thus creation of small $\operatorname{Co}(0)$ nanoparticles. It seems that the higher dispersion and smaller $\operatorname{Co}(0)$ nanoparticles in reduced $\mathrm{C}-\mathrm{Co}_{\mathrm{x}} \mathrm{SiBEA}$ than in reduced $\mathrm{Co}_{\mathrm{x}} \mathrm{AlBEA}$ can lead to obtain of the better catalytic properties in Fischer - Tropsch reaction.

\subsection{The catalytic activity of Red-C-Co $\mathrm{O}_{\mathrm{x}} \mathrm{SiBEA}$ and Red-C-Co $\mathrm{x}_{\mathrm{x}} \mathrm{AIBEA}$ in Fischer - Tropsch synthesis}

The Red-C-Co $\mathrm{SiBEA}_{\mathrm{x}}$ and Red-C-Co $\mathrm{AlBEA}$ catalysts were tested in Fischer Tropsch synthesis. $\mathrm{CO}$ conversion and selectivity towards $\mathrm{CH}_{4}, \mathrm{CO}_{2}$ and liquid products were analyzed. The influence of the Co content on the activity of Red-C-Co $\mathrm{SiBEA}_{\mathrm{x}} \mathrm{and}$ Red-C$\mathrm{Co}_{\mathrm{x}} \mathrm{AlBEA}$ in Fischer - Tropsch reaction is presented in Figure 10. The most active and selective catalyst towards liquid hydrocarbons appear Red-C-Co ${ }_{10} \mathrm{SiBEA}$ and Red-C-Co ${ }_{20} \mathrm{SiBEA}$ catalysts, obtained by two-step postsynthesis procedure. The $\mathrm{CO}$ conversion of 92 and $97 \%$ and the selectivities towards liquid products of 83 and $84 \%$ for Red-C-Co ${ }_{10} \mathrm{SiBEA}$ and Red-C-Co ${ }_{20} \mathrm{SiBEA}$ were achieved respectively.

For Red-C-Co $\mathrm{AlBEA}$ catalysts, the best activity and selectivity towards liquid products was found for Red-C-Co ${ }_{20} \mathrm{AlBEA}$ catalyst (CO conversion of $68 \%$; selectivity towards liquid hydrocarbons of $57 \%$ ). Red-C-Co ${ }_{10}$ AlBEA catalyst shows much lower activity than Red-C$\mathrm{Co}_{20} \mathrm{AlBEA}$ with $\mathrm{CO}$ conversion of $7 \%$ and selectivity towards liquid hydrocarbons of $53 \%$. 
Traditional used $\mathrm{Co} / \mathrm{Al}_{2} \mathrm{O}_{3}$ catalysts (containing 15 wt $\%$ of $\mathrm{Co}$ [29] or 7 wt \%), prepared by incipient wetness impregnation, showed CO conversion of $34.5-88.9 \%[29,30]$ and selectivity towards hydrocarbons $\mathrm{C}_{5+}$ of $81.5 \%\left(\mathrm{p}=20 \mathrm{Bar}, \mathrm{T}=220{ }^{\circ} \mathrm{C}\right)[29,30]$. It shows that Red-C-Co $\mathrm{Co}_{\mathrm{x}} \mathrm{SiBEA}$ zeolite catalysts prepared by two-step postsynthesis method are much more active than usually used cobalt supported $\mathrm{Al}_{2} \mathrm{O}_{3}$ catalysts. In contrast, Red-C$\mathrm{Co}_{\mathrm{x}} \mathrm{AlBEA}$ zeolite catalysts are a little less active than traditional used $\mathrm{Co} / \mathrm{Al}_{2} \mathrm{O}_{3}$ catalysts.

- Figure $10-$

The higher activity of Red-C-Co $\mathrm{C}_{\mathrm{x}} \mathrm{SiBEA}$ than Red-C-Co ${ }_{\mathrm{x}}$ AlBEA catalysts in Fischer Tropsch synthesis seems to be related to better cobalt dispersion and smaller cobalt nanoparticles size in the former than in the latter. The similar effect of Co dispersion on activity and selectivity of cobalt catalysts in Fischer - Tropsch reaction was earlier observed for $\mathrm{Co} / \mathrm{ITQ}$ [2] and $\mathrm{Co} / \mathrm{Y}$ [6]. The differences in selectivity towards $\mathrm{CH}_{4}$ and higher hydrocarbons were also observed during Fischer-Tropsch synthesis carried out on Co/ZSM 5, ZSM - 11, ZSM - 12 and ZSM - 34 zeolites [31]. The activity of these catalysts decreased in following order: ZSM-12 (12 MR) > ZSM-5 and ZSM-11 (10 MR) > ZSM-34 (8 MR) [31]. S. Bessels connected an increase of activity in Fischer-Tropsch synthesis with increasing of cobalt dispersion [31].

It is also found that the activity and selectivity of CoBEA zeolites changed with changing of the acidity of these materials. The acidity has influence on the kind of forming liquid products and on the amount and nature of carbon deposition. For the most active catalysts in FT synthesis (Red-C-Co ${ }_{20} \mathrm{AlBEA}$, Red-C-Co ${ }_{10} \mathrm{SiBEA}$ and Red-C-Co ${ }_{20} \mathrm{SiBEA}$ ), the changes of $\mathrm{CO}$ conversion and selectivity towards $\mathrm{CH}_{4}, \mathrm{CO}_{2}$ and liquid products versus time are shown in the Figures $11-13$. 
After $18 \mathrm{~h}$ time on stream on Red-C-Co ${ }_{20} \mathrm{AlBEA}$ catalyst, $\mathrm{CO}$ conversion decreases by $10 \%$ (from 68 to $58 \%$ ) with slight decreases of selectivity towards liquid hydrocarbons (from 54 to $52 \%$ ) and slight increases of selectivity towards $\mathrm{CH}_{4}$ (from 35 to $38 \%$ ) (Fig. 11).

- Figure 11 -

At the same time, on Red-C-Co ${ }_{10} \mathrm{SiBEA}$ catalyst one can observe a much higher decreases in CO conversion (from 90 to $44 \%$ ) and selectivity towards liquid products (from 83 to $76 \%$ ) and increases of selectivity towards $\mathrm{CH}_{4}$ (from 12 to $18 \%$ ) (Fig.12a). The most stable catalyst is Red-C-Co 20 SiBEA (Fig. 12b), for which any significant changes in $\mathrm{CO}$ conversion and selectivity towards liquid products are observed. In this case the $\mathrm{CO}$ conversion remains near $90 \%$ and selectivity towards liquid products near $85 \%$ after $20 \mathrm{~h}$ of reaction. The selectivity towards $\mathrm{CO}_{2}$ is stable and remains at the level of $5 \%$ for all catalysts under study.

-Figure 12 -

The liquid products fraction was analyzed using GC - MS technique. Results of this analysis are presented in the Figure 13 and quantitative analysis is showed in Table 3. During FT reaction carried out on Red-C-Cox AlBEA catalysts the main liquid products are saturated hydrocarbons $\left(\mathrm{C}_{7}-\mathrm{C}_{17}\right)$. The ratio of isoalkanes to n-alkanes is 0.10 for Red-C-Co ${ }_{10} \mathrm{AlBEA}$. In contrast, for Red-C-Co ${ }_{20}$ AlBEA only saturated hydrocarbons (n-alkanes) are observed (Fig. 13 and Table 3). On Red-C-Co $\mathrm{SiBEA}$ catalysts both saturated (n-alkanes and isoalkanes) and unsaturated $\left(\mathrm{C}_{7}-\mathrm{C}_{18}\right)$ hydrocarbons are identified (Figure 13). For Red-C-Co ${ }_{10}$ SiBEA catalyst the isoalkanes to n-alkanes ratio is 0.49 and ratio of olefins to n-alkanes is 0.16 . For Red-C-Co $\mathrm{Co}_{20} \mathrm{SiBEA}$ catalyst the isoalkanes to n-alkanes ratio is 0.28 . The ratio of unsaturated hydrocarbons to n-alkanes is 0.01 for Red-C- $\mathrm{Co}_{20} \mathrm{SiBEA}$ (Table 3).

The difference between identified liquid products for Red-C-Co $\mathrm{AlBEA}$ and Red-C$\mathrm{Co}_{\mathrm{x}} \mathrm{SiBEA}$ catalysts seems to be caused by the presence of various acidic sites in both types of catalysts. It is believed that hydrocarbons chain propagation occurs at metallic Co 
nanoparticles, located in extra-framework zeolite position and then formed hydrocarbons are transformed into lighter products, containing less n-alkanes, in line with earlier report [31].

- Figure 13 -

-Table 3 -

It is very interesting to understand what processes occur on zeolite catalysts during FT reaction and how the liquid hydrocarbons are formed. These studies are undertaken and will be subject of further publication.

The serious problem in Fischer - Tropsch synthesis is carbon deposition which blocks active sites of this reaction. We investigated amount and type of carbon deposit on both types of zeolites catalysts by TG - DTA - MS technique. The results are presented in Figure 14 and in Table 4. As it is seen the carbon deposition is higher for Red-C-Co $\mathrm{AlBEA}(12-18 \%)$ than for Red-C-Co $\operatorname{SiBEA}(11-12 \%)$ (Table 4). The oxidation of carbon occurs in two stages for Red-C-Co ${ }_{10} \mathrm{SiBEA}$, Red-C-Co ${ }_{20} \mathrm{SiBEA}$ and Red-C-Co ${ }_{20} \mathrm{AlBEA}$ catalysts. Both forms of carbon deposition are easily oxidised. The oxidation proceeds up to $500{ }^{\circ} \mathrm{C}$ (Fig. 14). In the case of Red-C-Co ${ }_{20} \mathrm{AlBEA}$ catalyst (Fig. 14a) two peaks of $\mathrm{CO}_{2}$ formation (MS profile) with maximum at $300{ }^{\circ} \mathrm{C}$ are assigned to removal of surface waxes or surface carbides forms whereas the peak with the maximum at $420{ }^{\circ} \mathrm{C}$ may be attributed to the removal of polymeric carbon, in line with earlier reports $[32,33,34]$. For Red-C-Co 20 SiBEA catalyst (Fig. 14b) two peaks of $\mathrm{CO}_{2}$ formation are also observed and both of them are probably related to removal of surface carbides forms or surface waxes, as suggested recently for $\mathrm{Co} / \mathrm{SiO}_{2}$ materials by Lee and Moodley [33,34].

-Figure $14-$

-Table 4 - 


\section{Conclusions}

Two different Co-containing zeolite systems were obtained by two different preparation procedures, $\mathrm{C}-\mathrm{Co}_{\mathrm{x}} \mathrm{AlBEA}$ by conventional wet impregnation and $\mathrm{C}-\mathrm{Co}_{\mathrm{x}} \mathrm{SiBEA}$ by two-step postsynthesis method. These zeolite systems showed different physicochemical properties related to Co species being in a weak and strong interaction with zeolite supports, respectively.

Red-C-Co ${ }_{x}$ SiBEA catalysts showed a very good catalytic activity in Fischer-Tropsch synthesis. The most active and stable catalysts were Red-C-Co ${ }_{10} \mathrm{SiBEA}$ and Red-C-Co ${ }_{20} \mathrm{SiBEA}$ with very high CO conversion (near 90 - $95 \%$ ) and selectivity towards liquid hydrocarbons (saturated n-alkanes and isoalkanes and unsaturated hydrocarbons) near $85 \%$.

Moreover the amount of carbon deposition on Red-C-Co $\mathrm{CiBE}_{\mathrm{x}} \mathrm{SiB}$ catalysts $(11-12 \%)$ was lower than that on Red-C-Co ${ }_{x}$ AlBEA catalysts $(12-18 \%)$.

The higher activity of Red-C-Co $\mathrm{SiBEA}$ than Red-C-Co $\mathrm{AlBEA}$ in Fischer-Tropsch synthesis was probably related to the higher dispersion of $\operatorname{Co}(0)$ nanoparticles with smaller size and particular acidic properties of former in comparison with the latter one.

\section{Acknowledgments}

T. Maniecki and P. Mierczynski are acknowledged for their kindly assistance in designing and setting the equipment for catalytic tests. T. Onfroy is acknowledged for FTIR measurements.

This work was financed by National Science Center (Poland) (Grant No. N N209 762140). 


\section{References}

1. T. Riedel, M. Claeys, H. Schulz, G. Schaub, S.-S. Nam, K.-W. Jun, M.-J. Choi, G. Kishan, K.-W. Lee, Appl. Catal. A 186 (1999) 201 - 213.

2. P. Concepcion, C. Lopez, A. Martinez, V. F. Puntes, J. Catal. 228 (2004) 321 - 332.

3. X. Li, J. He, M. Meng, Y. Yoneyama, N. Tsubaki, J. Catal. 265 (2009) 26 - 34.

4. A. N. Pour, Y. Zamani, A. Tavasoli, S. M. K. Shahri, S. A. Taheri,

Fuel 87 (2008) $2004-2012$.

5. A. Martinez, C. Lopez, Appl. Catal. A 294 (2005) 251 - 259.

6. Q. Tang, Y. Wang, Q. Zhang, H. Wan, Catal. Commun. 4 (2003) 253 - 258.

7. Z.-W. Liu, X. Li, K. Asami, K. Fujimoto, Catal. Today 104 (2005) 41 - 47.

8. C. Montes de Correa, F. C'ordoba Castrill’on, J. Mol. Catal. A 228 (2005) 267-273.

9. J. Rathousky, A. Zukal, A. Lapidus and A. Krylova, Appl. Catal. A 79 ( 1991 ) 167-180.

10. L. Guczi, I. Kiricsi, Appl. Catal. A 186 (1999) 375-394.

11. Y. Oumi, I. Jintsugawa, S. Kikuchi, S. Nawata, T. Fukushima, T. Teranishi, T. Sano, Micropor. Mesopor. Mat. 66 (2003) 109-116.

12. S. Dzwigaj, M. Che, J. Phys. Chem. B 110 (2006) 12490 - 12493.

13. J. Janas, T. Shishido, M. Che, S. Dzwigaj, Appl. Catal. B 89 (1 - 2) (2009) 196 - 203.

14. J. Janas, T. Machej, J. Gurgul, R.P. Socha, M. Che, S. Dzwigaj,

Appl. Catal. B 75 (2007) 239 - 248. 
15. M. Mhamdi, E. Marceau, S. Khaddar - Zine, A. Ghorbel, M. Che, Y. Ben Taarit,

F. Villain, Catal. Lett. 98 (2004) 135-140.

16. G. Fierro, M. A. Eberhardt, M. Houalla, M. H. Hercules, W. K. Hall,

J. Phys. Chem. 100 (1996) 8468-8477.

17. B.M. Weckhuysen, A.A. Verberckmoes, M.G. Uytterhoeven, F.E. Mabbs, D. Collison, E. de Boer, R.A. Schoonheydt, J. Phys. Chem. B 104 (2000) 37-42.

18. A.A. Verberckmoes, B.M. Weckhuysen, R.A. Schoonheydt,

Micropor. Mesopor. Mater. 22 (1998) 165-178.

19. W. Fan, B.M. Weckhuysen, R.A. Schoonheydt,

Phys. Chem. Chem. Phys. 3 (2001) 3240-3246.

20. W. Fan, R. Li, T. Dou, T. Tatsumi, B.M. Weckhuysen,

Micropor. Mesopor. Mater. 84 (2005) 116-126.

21. S. Thomson, V. Luca, R. F. Howe, Phys. Chem. Chem. Phys. 1 (1999) 615-619.

22. A. Eldewik, R. F. Howe, Micropor. Mesopor. Mater. 48 (2001) 65-71.

23. M. A. Camblor, A. Corma, S. Valencia, Micropor. Mesopor. Mater. 25 (1998) 59-74.

24. C.A. Emeis, J. Catal. 141 (1993) 347-354.

25. G. Jacobs, T. K. Das, Y. Zhang, J. Li, G. Racoillet, B. H. Davis, Appl. Catal. A 233 (2002) 263-281.

26. Y. Wang, M. Noguchi, Y. Takahashi, Y. Otsuka, Catal. Today 68 (2001) 3-9. 
27. S. J. Jong, S. Cheng, Appl. Catal. A 126 (1995) 51-66.

28. A. Martinez, G. Prieto, J. Catal. 245 (2007) 470 - 476.

29. D. Pena, A. Griboval-Constant, V. Lecocq, F. Diehl, A.Y. Khodakov, Catal. Today 215 (2013) $43-51$.

30. X. Li, J. He, M. Meng, Y. Yoneyama, N. Tsubaki, J. Catal. 265 (2009) 26-34.

31. S. Bessel, Appl. Catal. A 126 (1995) 235-244.

32. V. Gruver, R. Young, J. Engman, H.F. Robota, Prepr. Am. Chem. Soc., Div. Petrol. Chem. 50 (2005) 164-166.

33. D.K. Lee, J.H. Lee, S.K. Ihm, Appl. Catal. 36 (1988) 199-207.

34. D.J. Moodley, J. van de Loosdrecht, A.M. Saib, M.J. Overett, A.K. Datye, J.W. Niemantsverdriet, Appl. Catal. A 354 (2009) 102-110. 


\section{Table 1}

The average nanoparticles size for Red-C-Co ${ }_{20} \mathrm{AlBEA}$ and Red-C-Co ${ }_{20} \mathrm{SiBEA}$ catalysts calculated from TEM EDS data

\begin{tabular}{|c|c|}
\hline Sample & $\begin{array}{l}\text { Average crystallites size } \\
\qquad(\mathrm{nm})\end{array}$ \\
\hline Red-C-Co ${ }_{20} \mathrm{AlBEA}$ & 30.8 \\
\hline Red-C-Co 20 SiBEA & 14.3 \\
\hline
\end{tabular}

\section{Table 2}

The quantitative analysis of TPD- $\mathrm{NH}_{3}$ measurements

\begin{tabular}{cc} 
Sample & $\begin{array}{c}\text { The amount of adsorbed } \mathrm{NH}_{3} \\
\left(\mathrm{~mol} \mathrm{~g}^{-1}\right)\end{array}$ \\
\hline $\mathrm{C}-\mathrm{Co}_{10} \mathrm{AlBEA}$ & 2760 \\
$\mathrm{C}-\mathrm{Co}_{20} \mathrm{AlBEA}$ & 2440 \\
$\mathrm{C}-\mathrm{Co}_{10} \mathrm{SiBEA}$ & 1390 \\
$\mathrm{C}-\mathrm{Co}_{20} \mathrm{SiBEA}$ & 1010 \\
\hline
\end{tabular}


Table 3

The ratios of isoalkanes to n-alkanes and alkenes to n-alkanes calculated from GC-MS analysis data of liquid products obtained during FT reaction on various catalysts

\begin{tabular}{c|c|cc}
\hline Catalyst & iso/n-alkanes ratio & $\mathrm{C}_{\mathrm{n}} \mathrm{H}_{2 \mathrm{n}} / \mathrm{n}-\mathrm{C}_{\mathrm{n}} \mathrm{H}_{2 \mathrm{n}+2}$ ratio & Reference \\
\hline Red-C-Co $10 \mathrm{SiBEA}$ & 0.49 & 0.16 & This work \\
Red-C-Co ${ }_{10} \mathrm{AlBEA}$ & 0.10 & 0.00 & This work \\
Red-C-Co ${ }_{20} \mathrm{SiBEA}$ & 0.28 & 0.01 & This work \\
Red-C-Co ${ }_{20} \mathrm{AlBEA}$ & 0.00 & 0.00 & This work \\
$\mathrm{Co} / \mathrm{Al}_{2} \mathrm{O}_{3}$ & 0.02 & 0.07 & [30] \\
\hline
\end{tabular}




\section{Table 4}

Carbon deposit on Spent-Red-C-Co $\mathrm{AlBEA}$ and Spent-Red-C-Co $\mathrm{SiBEA}_{\mathrm{x}}$ catalysts after Fischer - Tropsch reaction

\begin{tabular}{|c|c|c|c|}
\hline Catalyst & $\begin{array}{c}\text { Total weight loss } \\
(\%)\end{array}$ & $\begin{array}{l}\text { Weight loss related } \\
\text { to } \mathrm{H}_{2} \mathrm{O} \text { removal } \\
(\%)\end{array}$ & $\begin{array}{l}\text { Weight loss related } \\
\text { to carbon deposition } \\
\text { oxidation } \\
(\%)\end{array}$ \\
\hline $\begin{array}{l}\text { Spent-Red-C- } \\
\text { Co }_{10} \text { AlBEA }\end{array}$ & & 3.8 & 11.6 (1 step) \\
\hline $\begin{array}{l}\text { Spent-Red-C- } \\
\mathrm{Co}_{10} \mathrm{SiBEA}\end{array}$ & 15.8 & 4.9 & 10.8 (2 steps) \\
\hline $\begin{array}{l}\text { Spent-Red-C- } \\
\mathrm{Co}_{20} \mathrm{AlBEA}\end{array}$ & 21.2 & 3.3 & 17.9 (2 steps) \\
\hline $\mathrm{Co}_{20} \mathrm{SiBEA}$ & 14.4 & 2.1 & 12.4 (2 steps) \\
\hline
\end{tabular}




\section{Figure captions :}

Figure 1. DR UV - vis spectra of $\mathrm{Co}_{20} \mathrm{AlBEA}, \mathrm{Co}_{10} \mathrm{SiBEA}$ and $\mathrm{Co}_{20} \mathrm{SiBEA}$ recorded at room temperature and ambient atmosphere.

Figure 2. DR UV - vis spectra of $\mathrm{C}-\mathrm{Co}_{20} \mathrm{AlBEA}$ and $\mathrm{C}-\mathrm{Co}_{20} \mathrm{SiBEA}$ recorded at room temperature and ambient atmosphere.

Figure 3. XRD patterns of $\mathrm{C}-\mathrm{Co}_{10} \mathrm{AlBEA}$ and $\mathrm{C}-\mathrm{Co}_{20} \mathrm{AlBEA}$ recorded at room temperature and ambient atmosphere.

Figure 4. XRD patterns of $\mathrm{C}-\mathrm{Co}_{10} \mathrm{SiBEA}$ and $\mathrm{C}-\mathrm{Co}_{20} \mathrm{SiBEA}$ recorded at room temperature and ambient atmosphere.

Figure 5. TPD $-\mathrm{NH}_{3}$ profiles of $\mathrm{C}-\mathrm{Co}_{10} \mathrm{AlBEA}$ and $\mathrm{C}-\mathrm{Co}_{20} \mathrm{AlBEA}$.

Figure 6. TPD $-\mathrm{NH}_{3}$ profiles of $\mathrm{C}-\mathrm{Co}_{10} \mathrm{SiBEA}$ and $\mathrm{C}-\mathrm{Co}_{20} \mathrm{SiBEA}$

Figure 7. TPR $-\mathrm{H}_{2}$ profiles of $\mathrm{C}-\mathrm{Co}_{10} \mathrm{AlBEA}$ and $\mathrm{C}-\mathrm{Co}_{20} \mathrm{AlBEA}$.

Figure 8. TPR $-\mathrm{H}_{2}$ profiles of $\mathrm{C}-\mathrm{Co}_{10} \mathrm{SiBEA}$ and $\mathrm{C}-\mathrm{Co}_{20} \mathrm{SiBEA}$.

Figure 9. TEM images of R-C-Co ${ }_{20} \mathrm{AlBEA}$ (a) and R-C-Co ${ }_{20} \mathrm{SiBEA}(\mathrm{b})$.

Figure 10. The conversion of $\mathrm{CO}$ and selectivity towards $\mathrm{CO}_{2}, \mathrm{CH}_{4}$ and liquid hydrocarbons after $15 \mathrm{~h}$ of reaction at $260{ }^{\circ} \mathrm{C}$ and 30 atm on Red-C-Co ${ }_{10}$ AlBEA, Red-C-Co ${ }_{20}$ AlBEA, Red-C-Co ${ }_{10} \mathrm{SiBEA}$ and Red-C-Co 20 SiBEA catalysts.

Figure 11. Changes of $\mathrm{CO}$ conversion and selectivity towards $\mathrm{CO}_{2}, \mathrm{CH}_{4}$ and hydrocarbons $\mathrm{C}_{2+}$ versus time for Red-C-Co ${ }_{20}$ AlBEA catalyst.

Figure 12. Changes of $\mathrm{CO}$ conversion and selectivity towards $\mathrm{CO}_{2}, \mathrm{CH}_{4}$ and hydrocarbons $\mathrm{C}_{2+}$ versus time for Red-C-Co ${ }_{10} \mathrm{SiBEA}$ catalyst (a) and for Red-C-Co ${ }_{20} \mathrm{SiBEA}$ catalyst (b). 
Figure 13. GC - MS analysis of liquid products obtained in FTS carried out on Red-C$\mathrm{Co}_{10} \mathrm{AlBEA}$ catalyst (a), Red-C-Co ${ }_{10} \mathrm{SiBEA}$ catalyst (b), Red-C-Co ${ }_{20} \mathrm{AlBEA}$ (c) and Red-C$\mathrm{C}_{20} \operatorname{SiBEA}(\mathrm{d})$.

Figure 14. DTG, DTA and MS analysis of Spent-Red-C-Co ${ }_{20}$ AlBEA (a) and Spent-Red-C$\mathrm{Co}_{20} \mathrm{SiBEA}$ catalyst (b). 


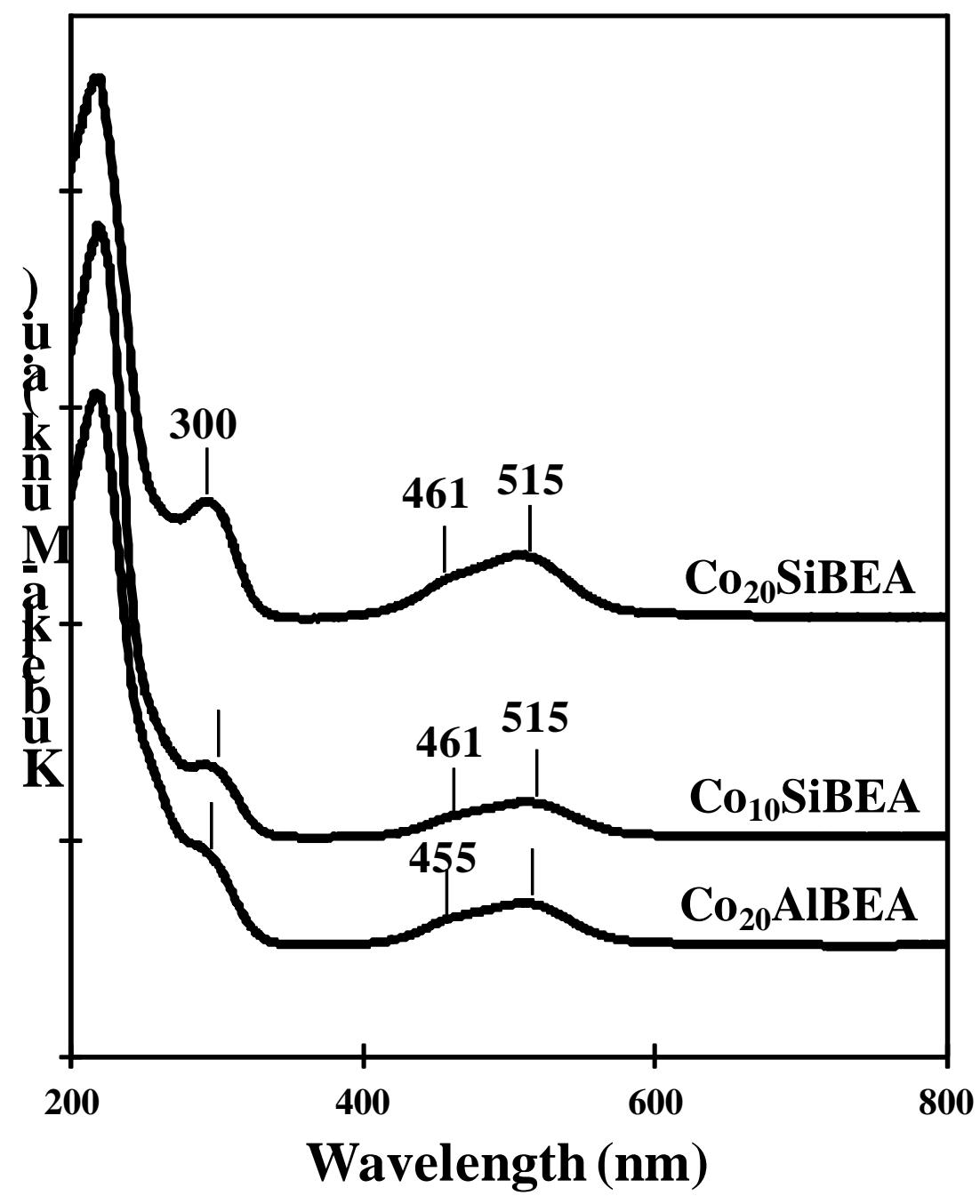

-Figure 1 - 


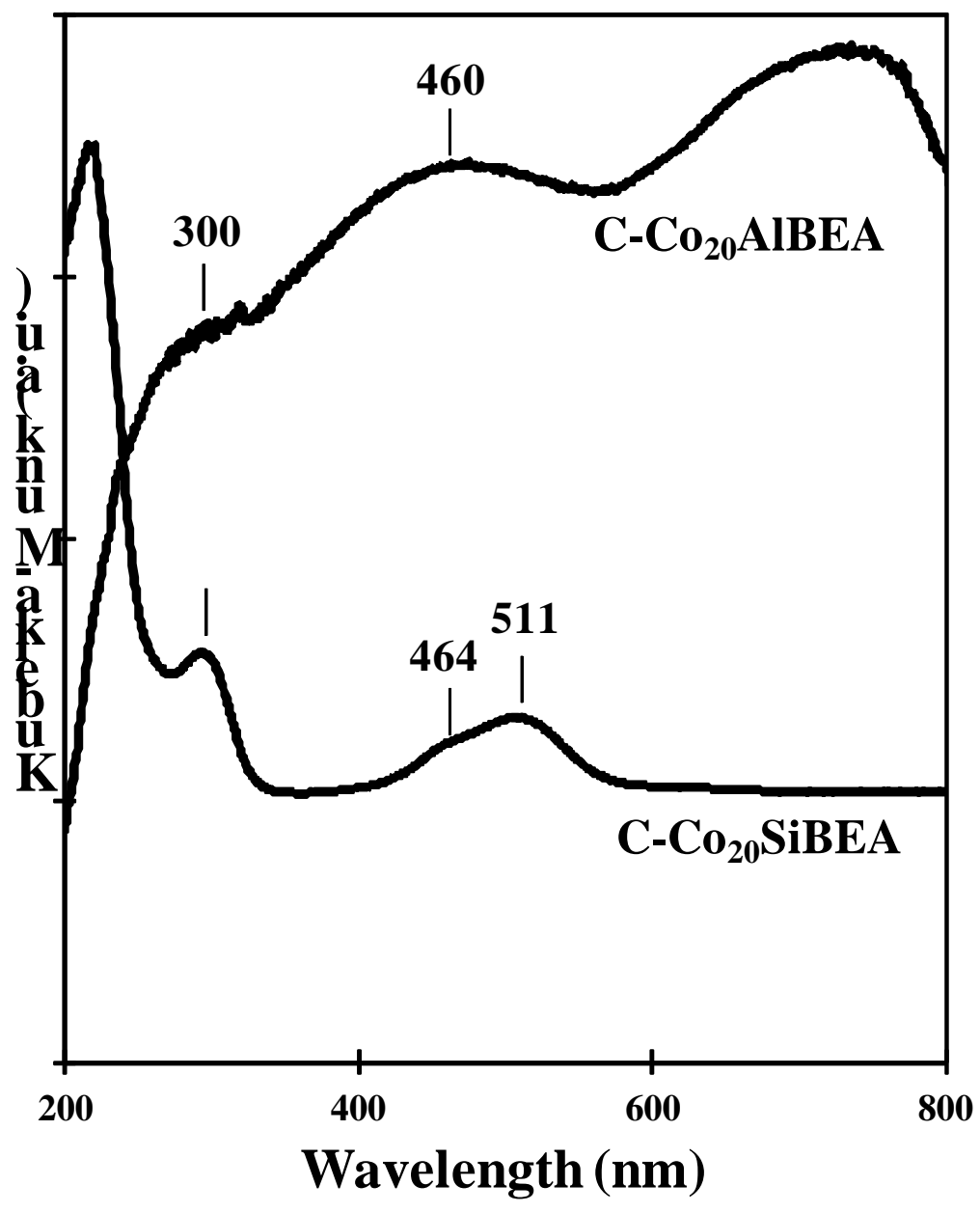

-Figure 2 - 


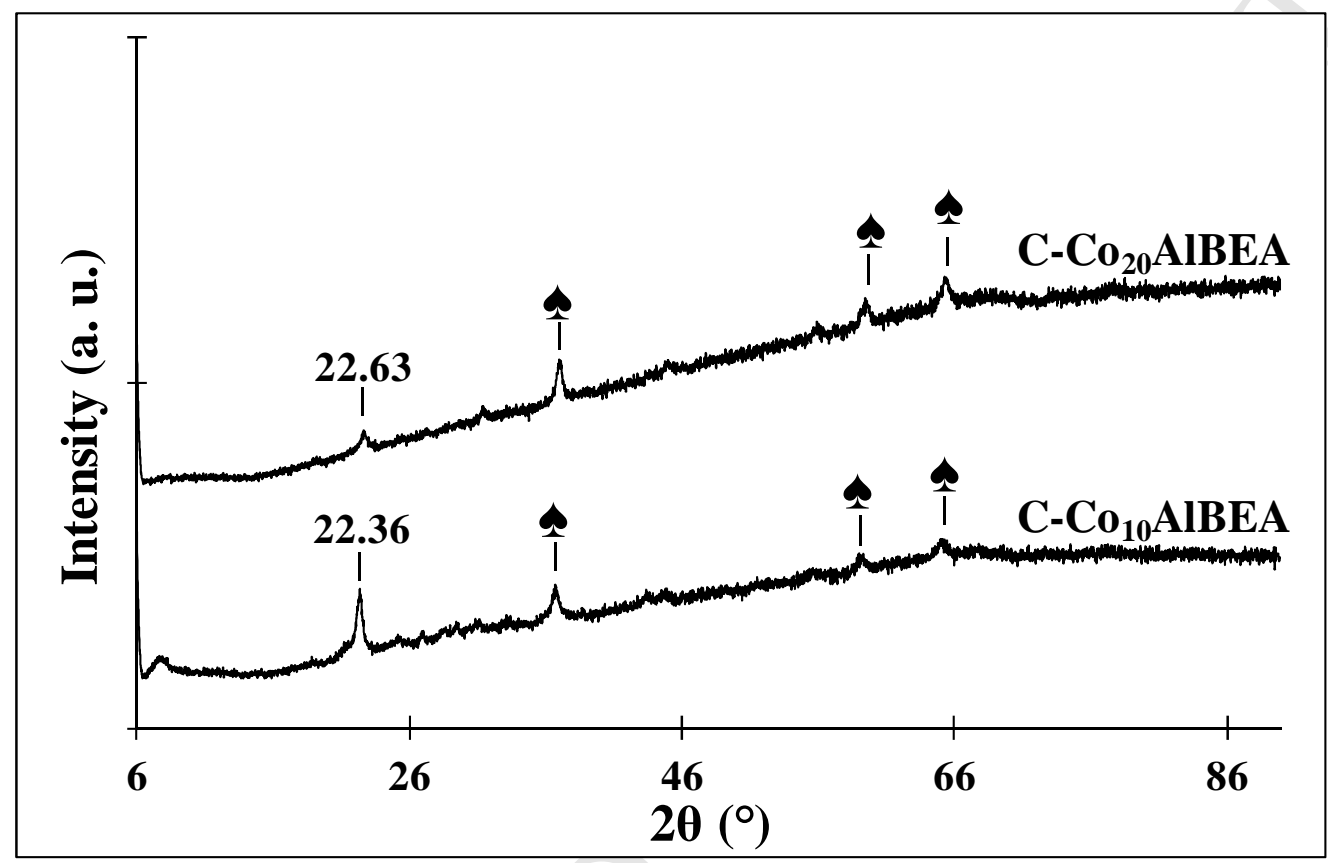

-Figure 3 - 


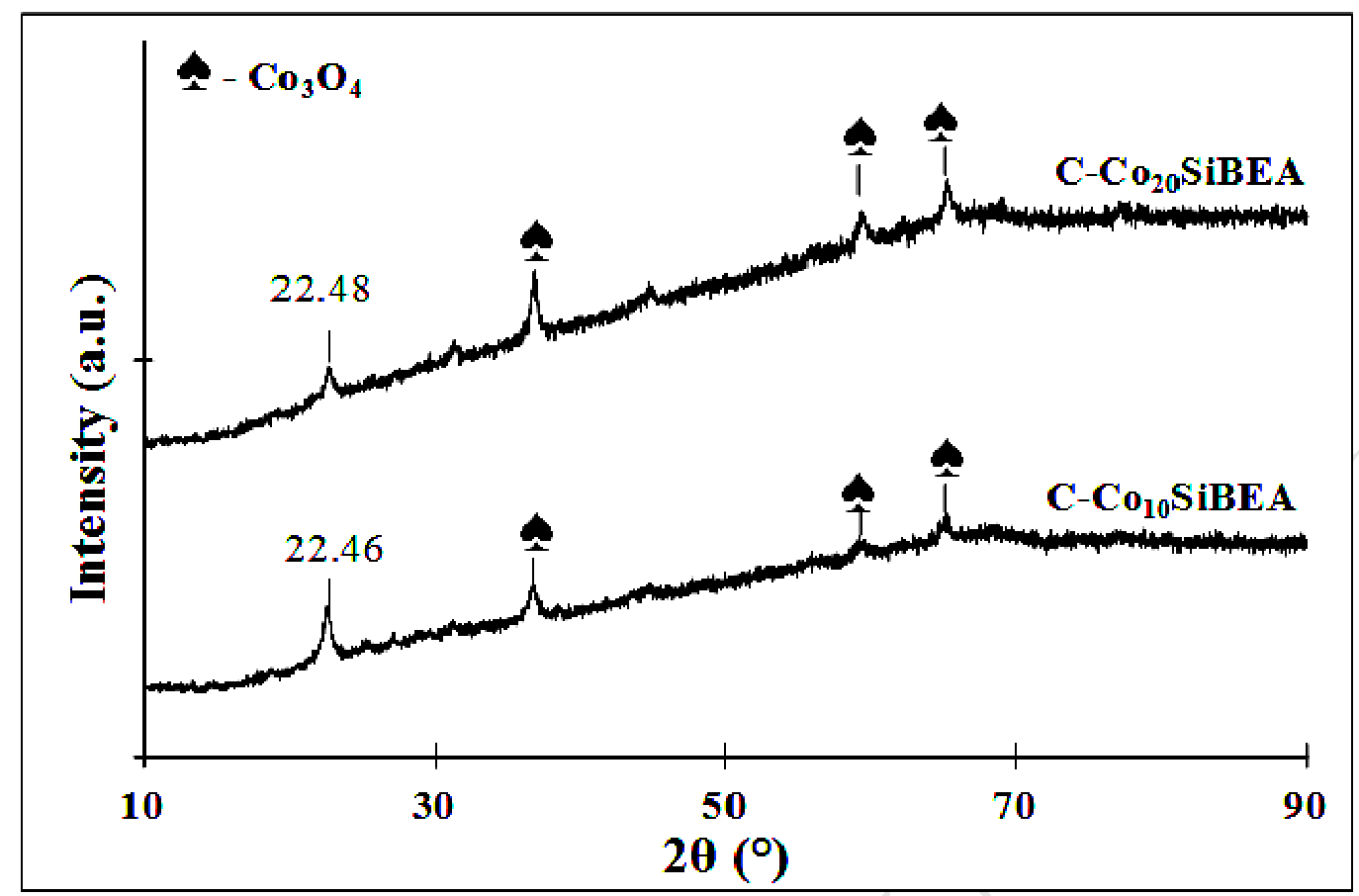

-Figure 4 - 


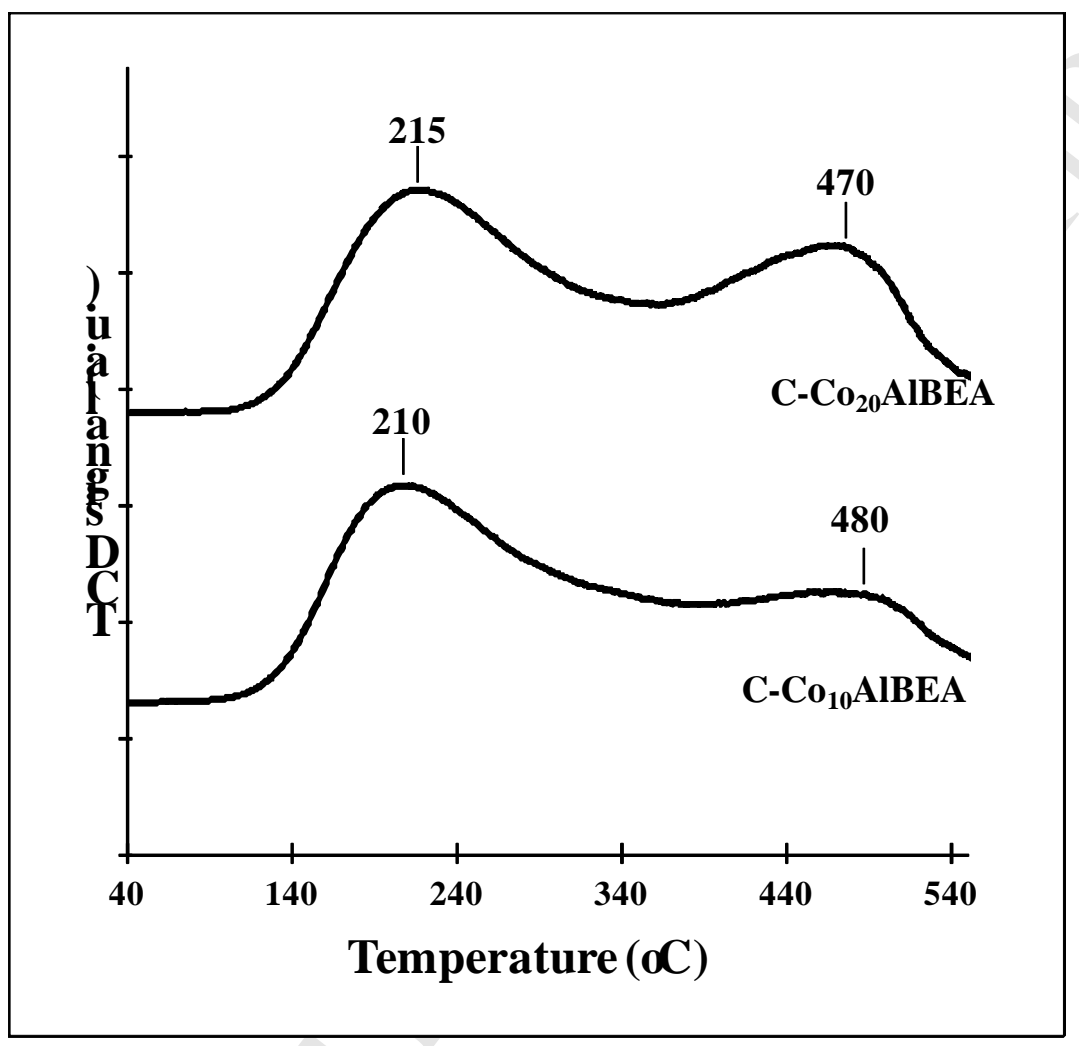

-Figure 5 - 


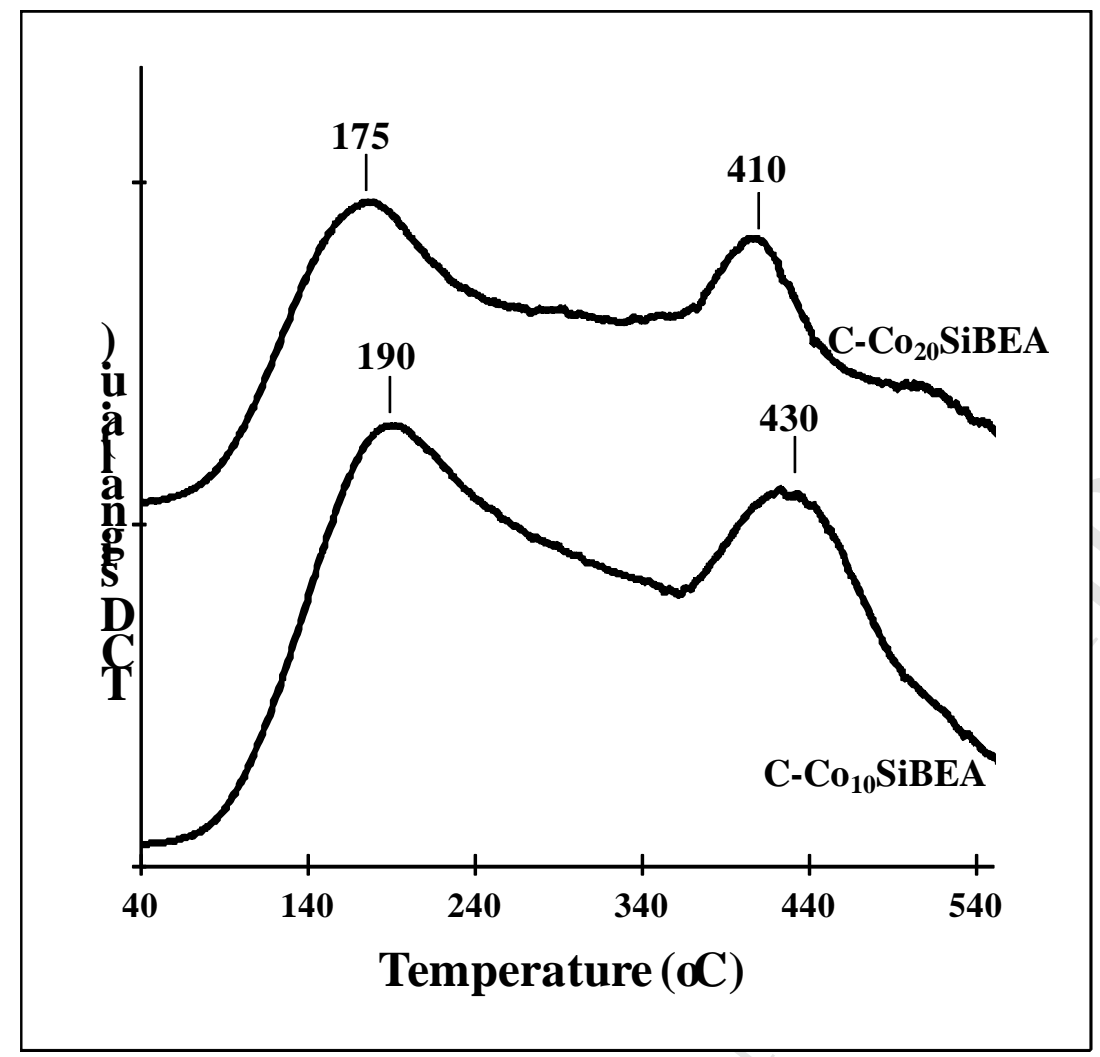

-Figure 6- 


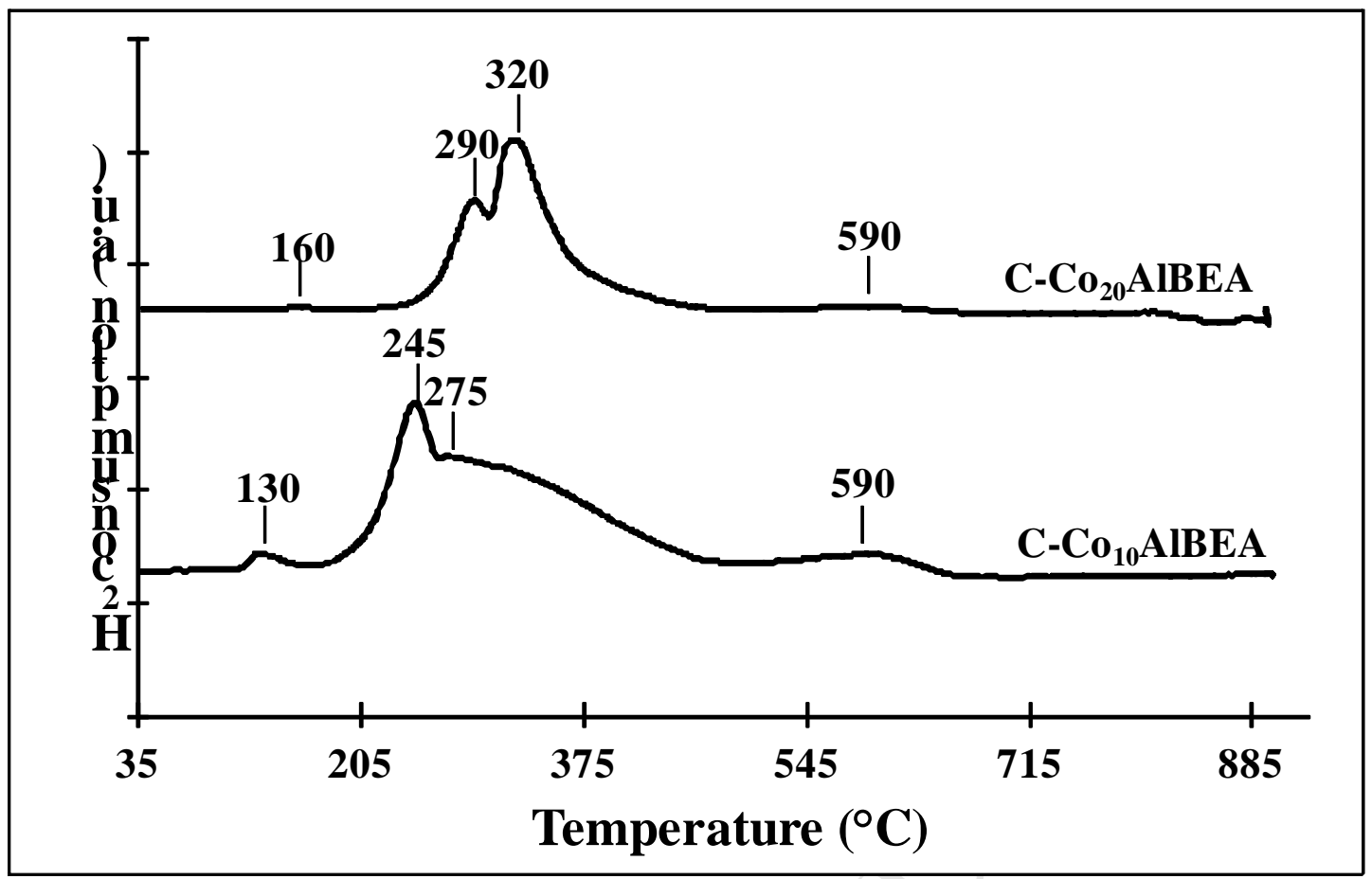

Figure 7 


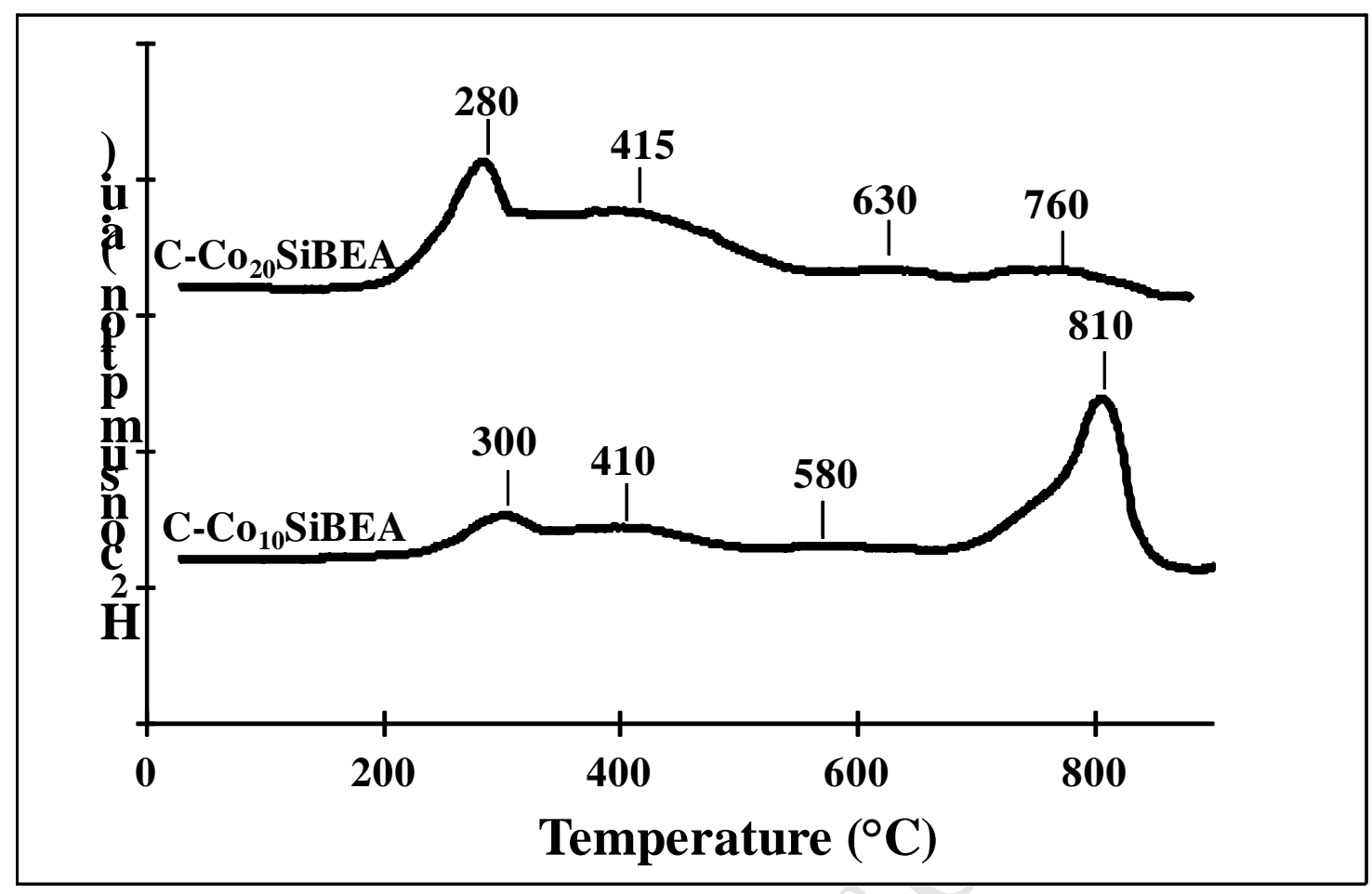

-Figure 8 - 


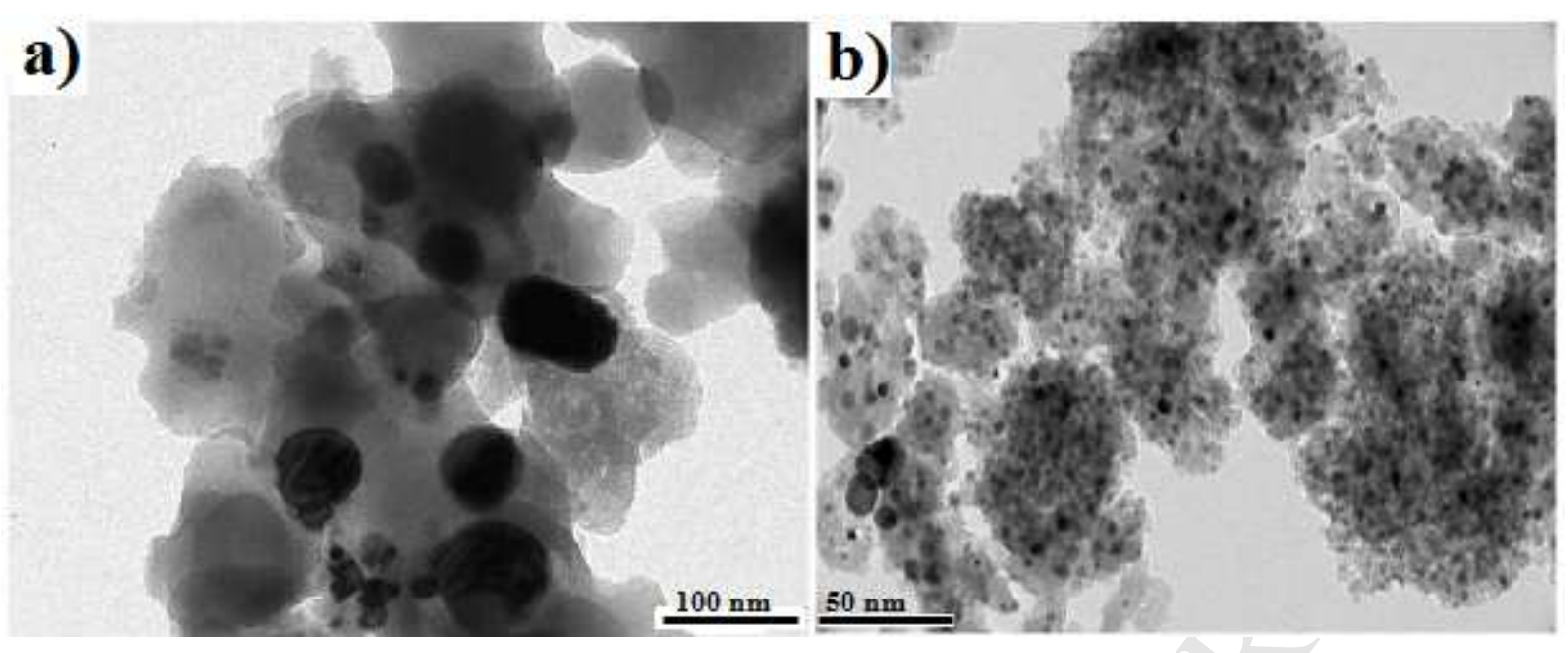

Figure 9 


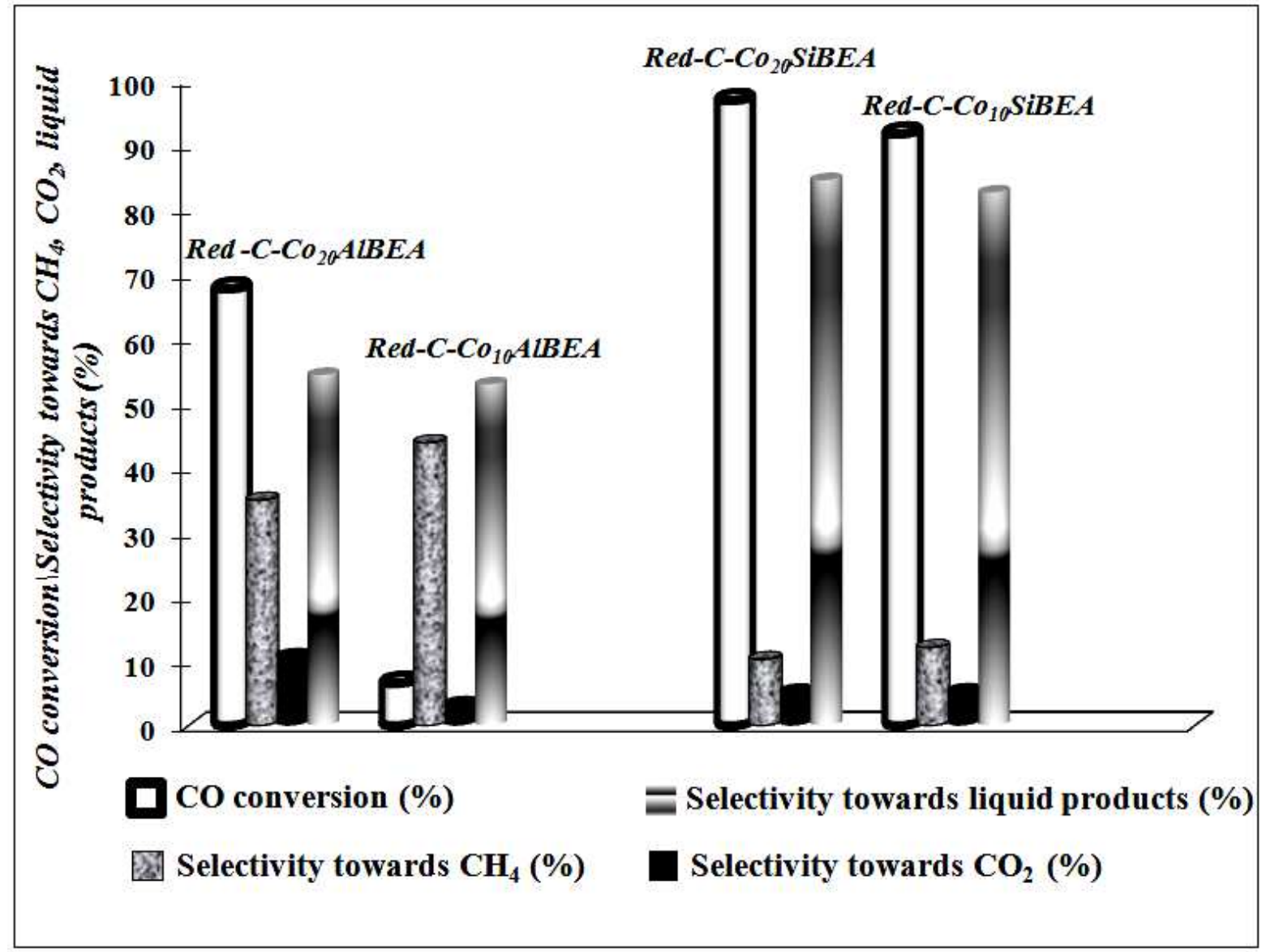

-Figure 10 - 
$\operatorname{Red}-\mathrm{C}-\mathrm{Co}_{2 \theta^{\circ}} \mathrm{AlBEA}\left(\mathrm{T}=260^{\circ} \mathrm{C} ; \mathrm{p}=30 \mathrm{~atm}\right)$

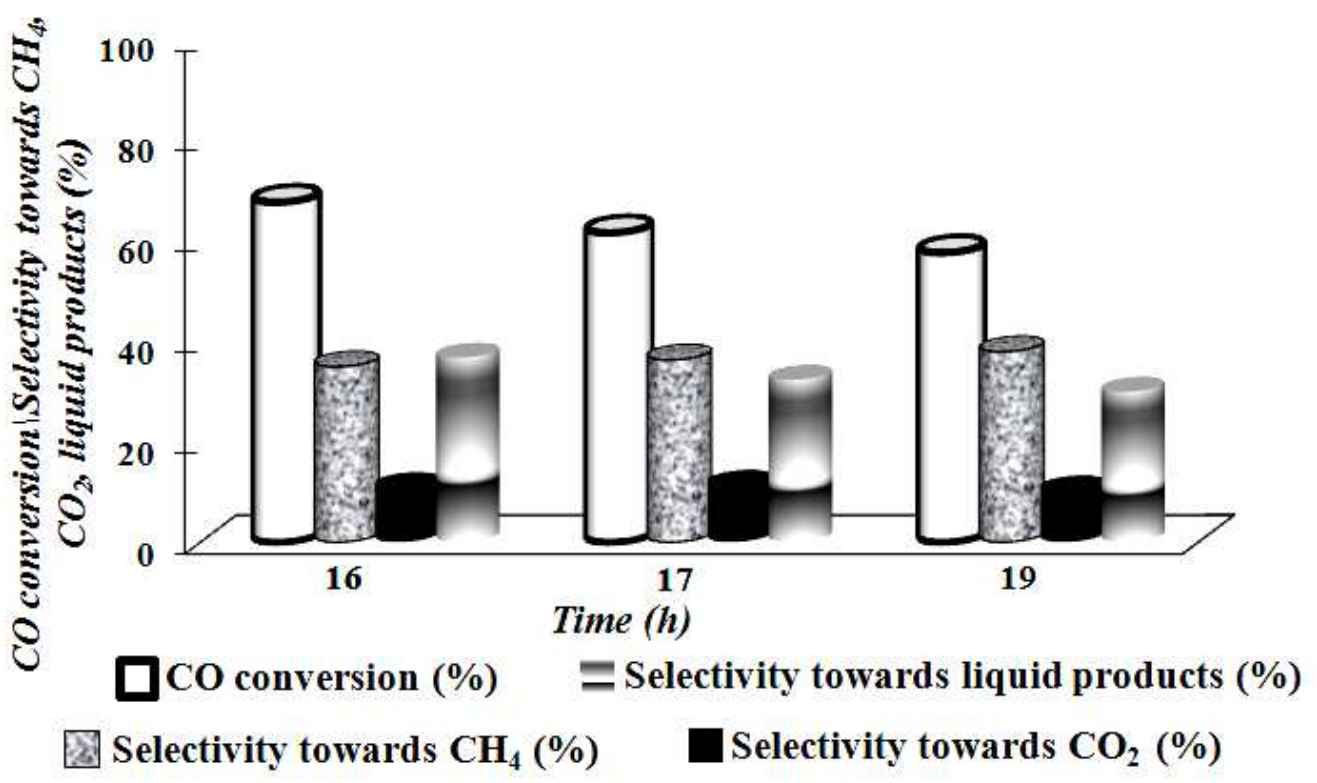

-Figure 11 - 


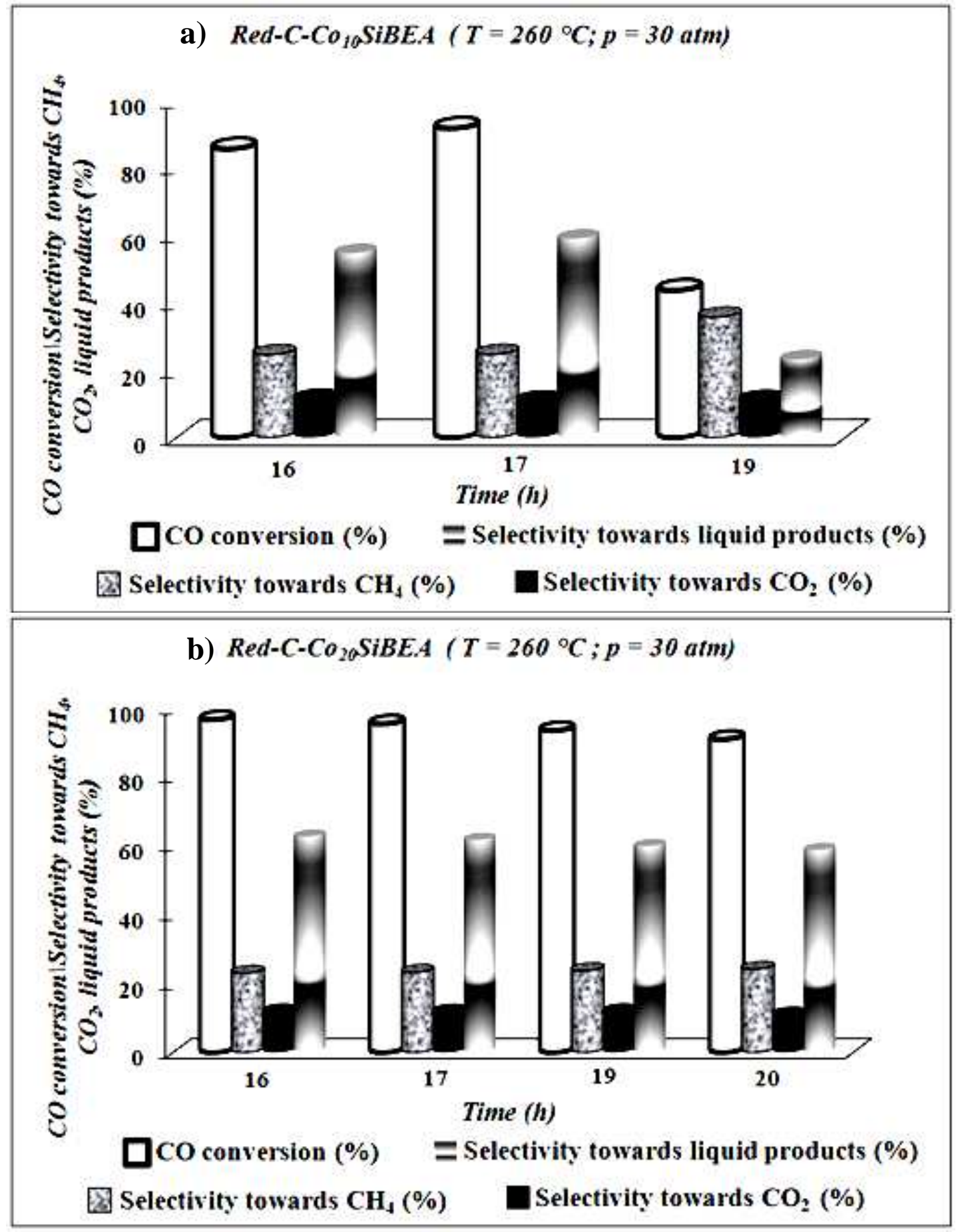

-Figure 12 - 

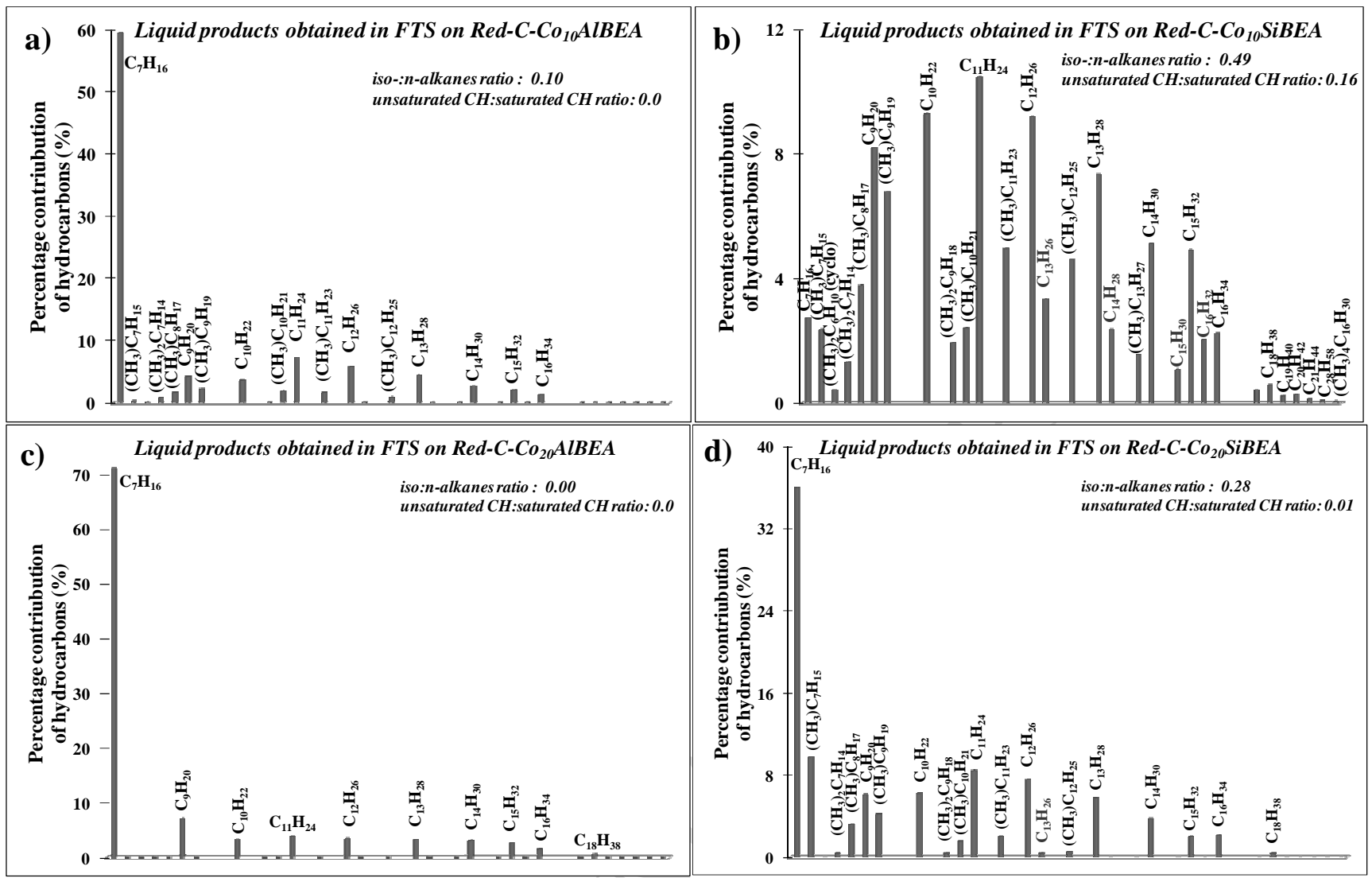

-Figure 13 - 

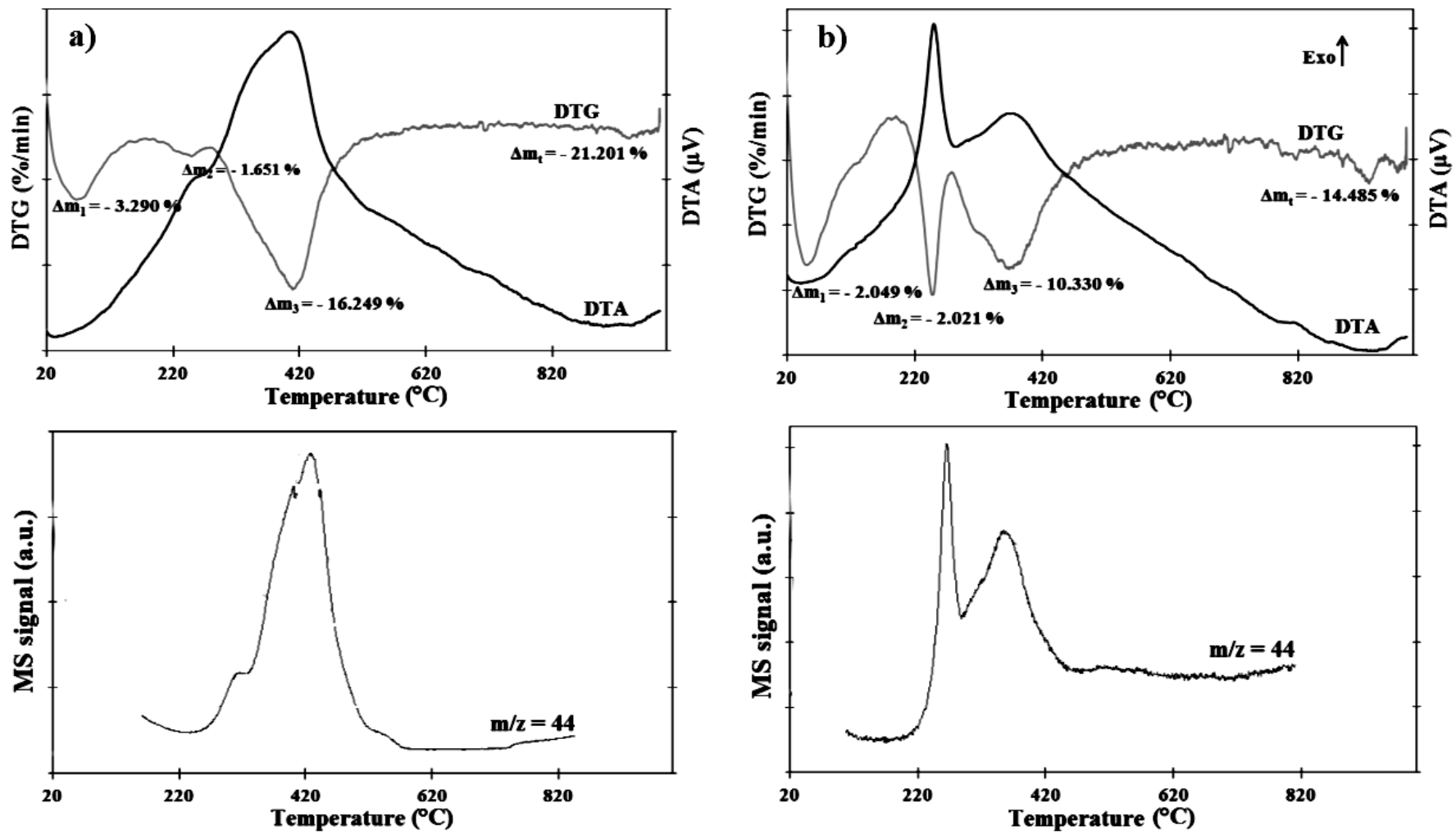

-Figure 14 - 


\section{Highlights:}

- The most active catalysts were Red-C-Co $\mathrm{SiBEA}_{\mathrm{x}}$ with high $\mathrm{CO}$ conversion of $90-95$ $\%$.

- The selectivity towards liquid hydrocarbons $\left(\mathrm{C}_{7}-\mathrm{C}_{18}\right)$ on these catalysts was $85 \%$.

- Cobalt nanoparticles in Red-C-Co ${ }_{x} \mathrm{SiBEA}$ were much better dispersed than that in Red-C-Co ${ }_{x}$ AlBEA

- The carbon deposition on Red-C-Co $\mathrm{SiBEA}_{\mathrm{x}}$ was lower than that on Red-C-Co $\mathrm{A} A \mathrm{BEEA}$ 